\title{
COMPARISON OF FOAMING PROPERTIES BETWEEN CHELATED RECONSTITUTED SMP AND CASEINATES
}

\author{
A Thesis \\ presented to the \\ Faculty of California Polytechnic State University, \\ San Luis Obispo \\ In Partial Fulfillment \\ of the Requirements for the Degree \\ Master of Science in Agriculture, \\ With Specialization in Dairy Products Technology
}

By Boya Liu

June 2016 
(C)2016

Boya Liu

ALL RIGHTS RESERVED 
COMMITTEE MEMBERSHIP

TITLE: Comparison of Foaming Properties between Chelated

Reconstituted SMP and Caseinates

AUTHOR: Boya Liu

DATE SUBMITTED: June 2, 2016

COMMITTEE CHAIR: Vincent Yeung, Ph.D., Assistant Professor

Animal Science Department

California Polytechnic State University

San Luis Obispo

COMMITTEE MEMBER: Philip S. Tong, Ph.D., Professor

Animal Science Department

California Polytechnic State University

San Luis Obispo

COMMITTEE MEMBER: Hunter Glanz, Ph.D., Assistant Professor

Statistics Department

California Polytechnic State University

San Luis Obispo 


\section{ABSTRACT}

Comparison of Foaming Properties between Chelated Reconstituted SMP and Caseinates

Boya Liu

Caseinate powders have been well accepted because of their foaming properties. In this study, $10 \%$ solution of reconstituted skim milk powder (SMP) chelated with sodium hexametaphosphate (SHMP) and trisodium citrate (TSC) at $1 \mathrm{mEq}, 50 \mathrm{mEq}$ and $100 \mathrm{mEq}$ were prepared to conduct a comparison with sodium caseinate, potassium caseinate, and calcium caseinate solutions. Foamability, foam stability as well as the preferential locations of $\alpha_{\mathrm{s}}$-casein, $\beta$-casein and $\kappa$-casein in their foams were analyzed. It was hypothesized that the foamability, foam stability and the preferential locations of these three caseins in the milk foams are different from treatment to treatment. Milk foam was generated with an airinjection method at a flow rate of $0.30 \mathrm{~L} / \mathrm{M}$ for 18 seconds. Foam stability was measured through half-life method. The foam composition was quantified with sodium dodecyl sulfate-polyacrylamide gel electrophoresis (SDS-PAGE) method. Analysis of Variance (ANOVA) test results concluded that there were no significant differences detected in foamability $(p>0.05)$. On the other hand, foam stability differed significantly among the treatments. Foams of reconstituted SMP treated with $1 \mathrm{mEq}$ SHMP and TSC were significantly more stable compared to other treatments $(p<0.05)$. No differences were found in the preferential 
locations of $\alpha_{s}$-casein $(p>0.05), \beta$-casein $(p>0.05)$ and $\kappa$-casein $(p>0.05)$.

In conclusion, the addition of calcium chelating salts might increase the foamability to the same level as caseinate solutions. Furthermore, the study proved that the combination of calcium chelating salts and chelator levels is able to alter the foam stability.

Keywords: casein, calcium chelating salts, foamability, foam stability, preferential locations 


\section{ACKNOWLEDGMENTS}

My heart is full of gratitude in my two-year experience in Cal Poly. The friendly and enthusiastic staff in Cal Poly made my graduate student life much more meaningful. I would not be as skillful and professional as I currently am without the extraordinary education I received here in San Luis Obispo.

I am also grateful for my parents for the moral and financial support for my undergraduate and graduate education. Moreover, their being role models in my life teach me to be a responsible person.

It is such an honor and pleasure to have gained training and guidance from Dr. Philip Tong, who not only efficiently delivers knowledge to his students, but also encouraged us to think more as dairy scientists. The expertise and support shared by other committee members: Dr. Hunter Glanz and Dr. Vincent Yeung, laid a solid foundation for my path to finish this project.

The generous support I received from DPTC was also appreciated. Sean Vink and Matt Arnold walked me through various experimental procedures and helped me locate and fix various problems in my experiments.

I would like to thank my DPTC friends who unselfishly share their knowledge and help. My memories with them will be remembered forever. I want to represent my special gratitude to my best friend Haiwen He who always stand by me to offer his advice and Jeff Wilbur for keeping me updated about the dairy industry.

I sincerely appreciate all the people who helped me through my graduate program. Their involvements made my life vivid and fantastic. 


\section{TABLE OF CONTENTS}

LIST OF TABLES.

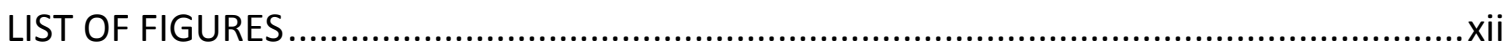

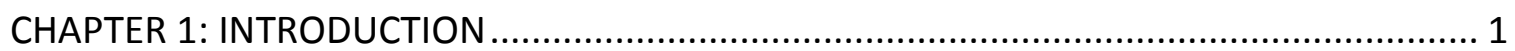

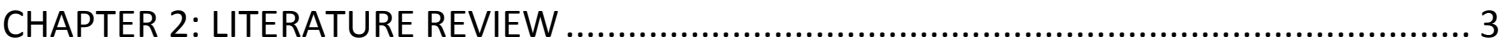

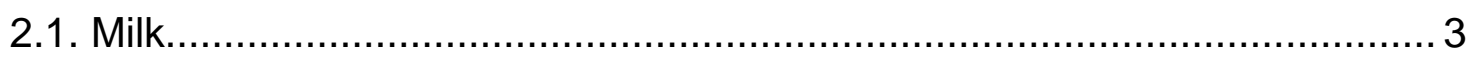

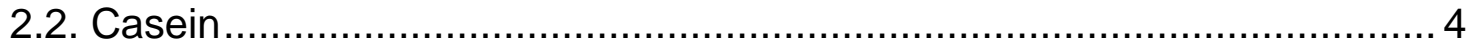

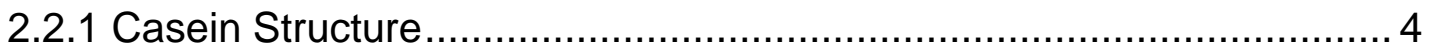

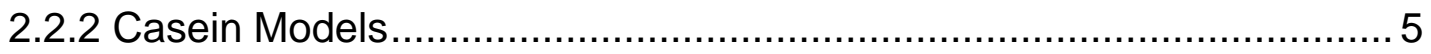

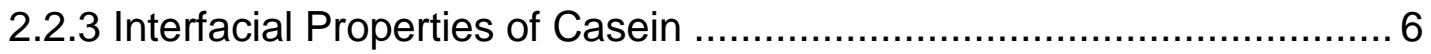

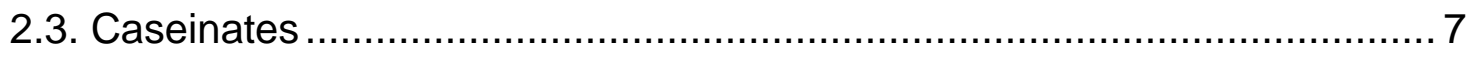

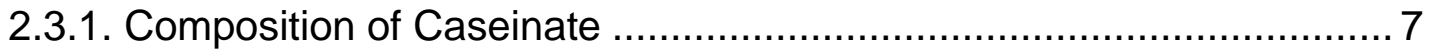

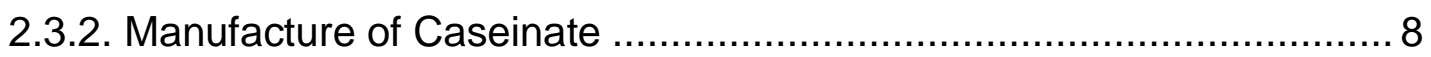

2.3.3. Disadvantages of Caseinates .............................................. 8

2.3.4 Foaming Properties of Caseinates ........................................ 8

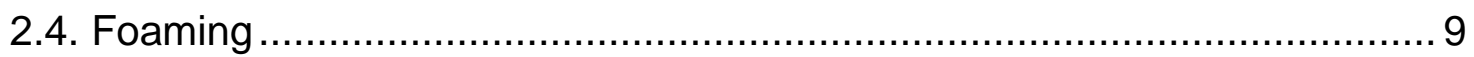

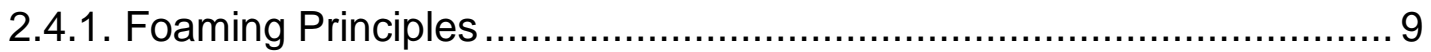

2.4.2. Milk Foam Composition .............................................. 13

2.4.3. Factors Influencing the Foaming Properties of Milk ...................... 13

2.4.4. Influence of Electric Charges on the Foaming Properties of Milk ...... 14

2.4.5. Influences of Temperature on Milk Foaming Properties .................. 14

2.4.6. Influences of Oil on Milk Foaming Properties .............................. 15

2.4.7. Milk Foaming Methods ................................................... 15 


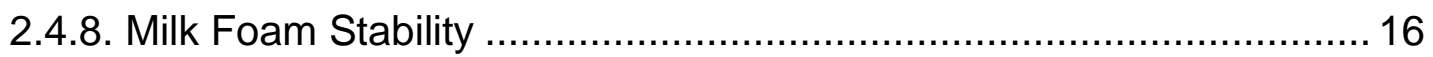

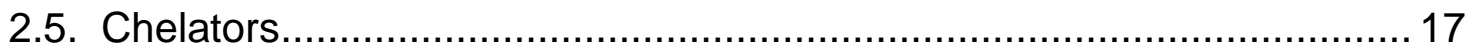

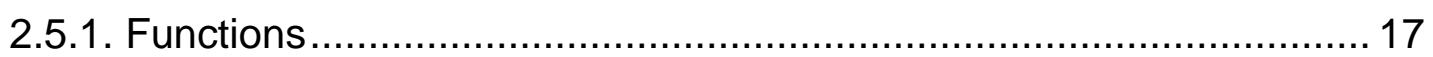

2.5.2. Influences of Chelators on Dairy Products ..................................... 17

2.5.3. Influence of Calcium Chelating Salts on the Foaming Properties ...... 18

2.6. Rationale, Objective and Hypothesis ............................................... 18

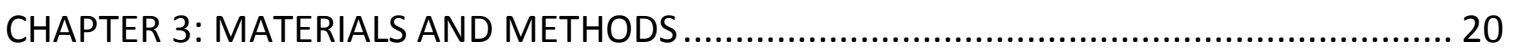

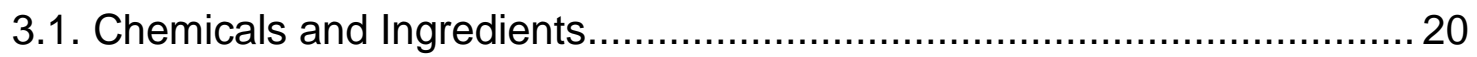

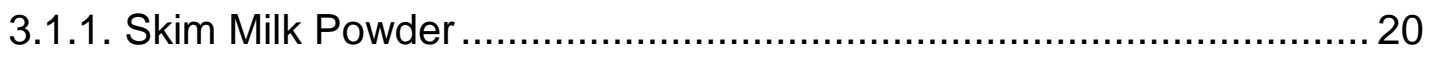

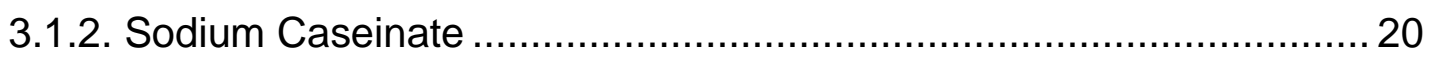

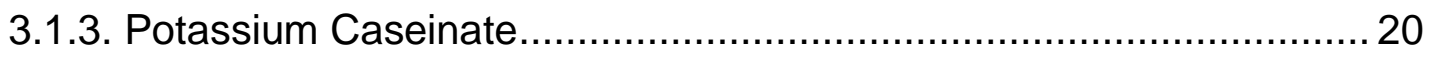

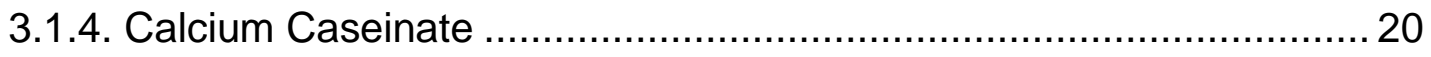

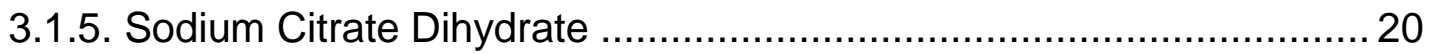

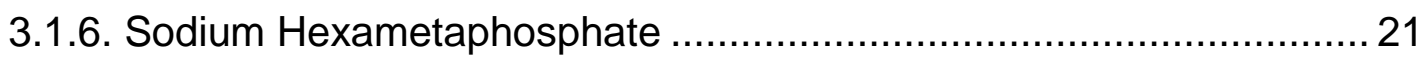

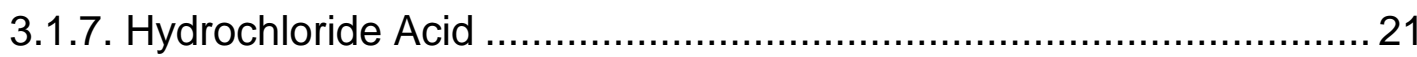

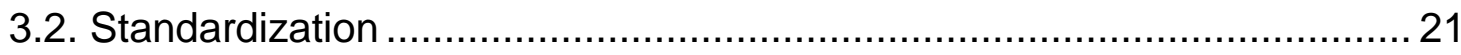

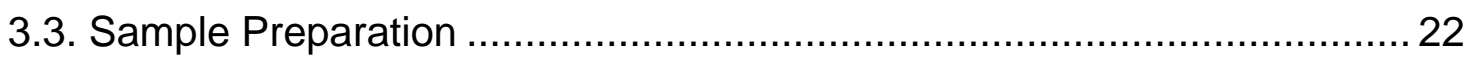

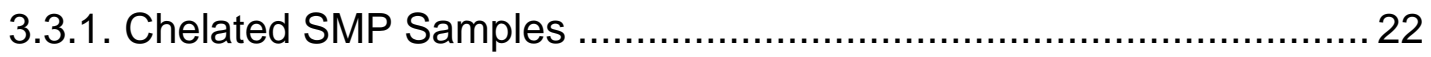

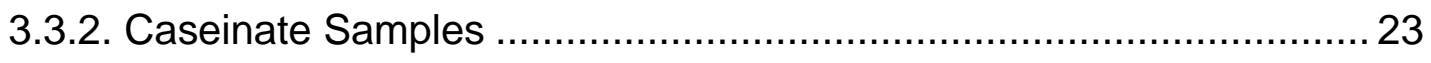

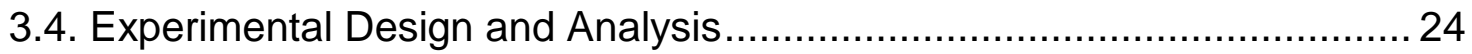

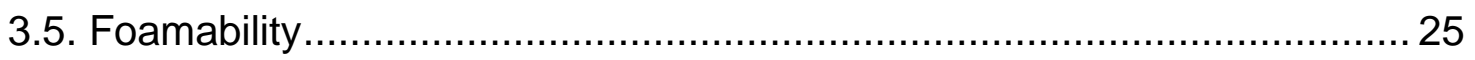

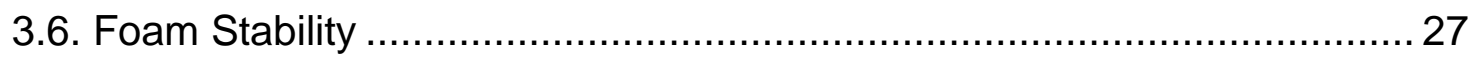

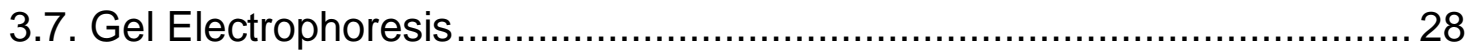




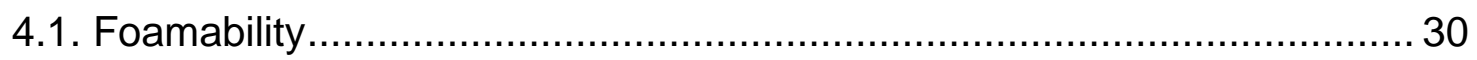

4.2. Effects of Calcium Chelating Salts on Foamability ................................ 33

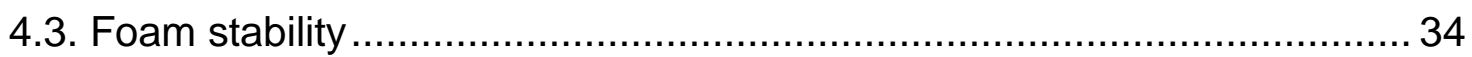

4.4. Effects of Calcium Chelating Salts on Foam Stability …......................... 36

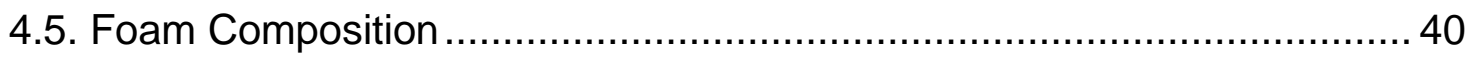

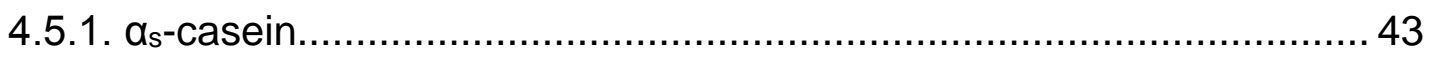

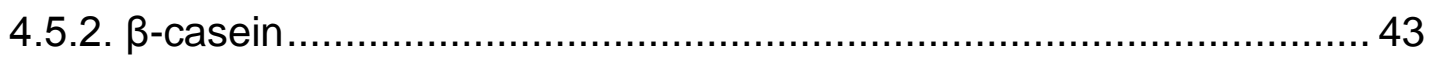

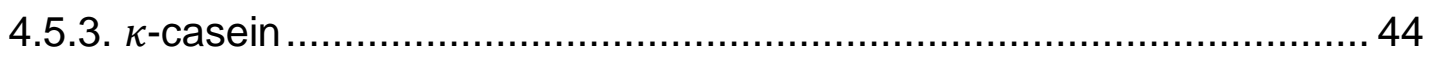

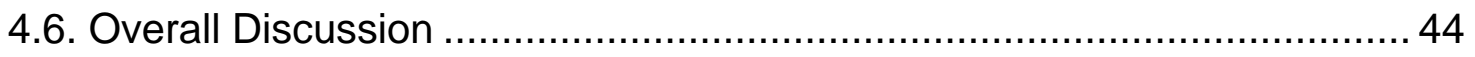

CHAPTER 5: CONCLUSION AND SIGNIFICANCE OF FINDINGS ........................................ 46

CHAPTER 6: LIMITATIONS AND DIRECTIONS FOR FUTURE RESEARCH .......................... 47

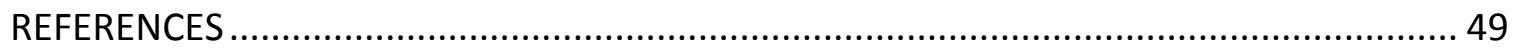

$\begin{array}{ll}\text { APPENDICES } & 57\end{array}$

1. Statistical Analysis of Foamability among all Treatments. ........................57

2. Statistical Analysis of Foamability among Chelated Reconstituted SMP. ... 58

3. Statistical Analysis of Foam Stability among all Treatments.....................59

4. Statistical Analysis of Foam Stability among Chelated Reconstituted

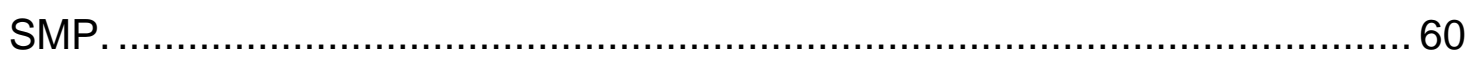

5. Statistical Analysis of Preferential Locations of $\alpha_{s}$-casein......................... 61

6. Statistical Analysis of Preferential Locations of $\beta$-casein. ......................... 62

7. Statistical Analysis of Preferential Locations of $\kappa$-casein. ......................... 63 
8. Foamability $(\mathrm{mL})$ and Half-life $(\mathrm{min})$ of Non-treated SMP and Micellar Casein Solutions. .

9. Statistical Analysis on the Foamability between the Non-treated SMP and Micellar Casein Solutions.

10. Statistical Analysis on the Foam Stability between the Non-treated SMP and Micellar Casein Solutions. 


\section{LIST OF TABLES}

Table 1: Nutrition composition of 1 serving size of whole milk in Standard

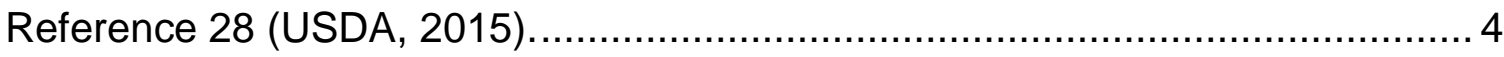

Table 2: Amounts of SMP, Chelator and Deionized water in each

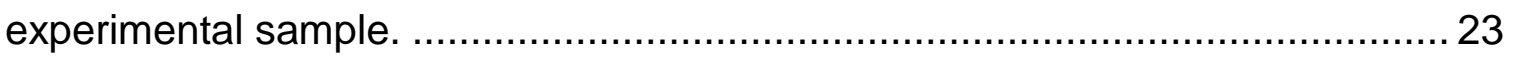

Table 3: Composition of caseinate samples.............................................. 24

Table 4: Mean value, standard deviation and $95 \%$ confidence interval of

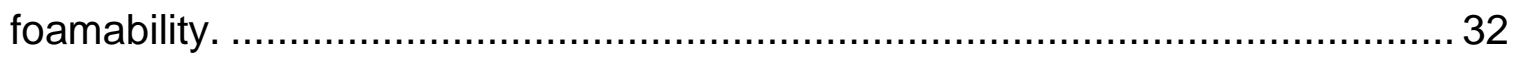

Table 5: Mean value, standard deviation and 95\% confidence interval of foam

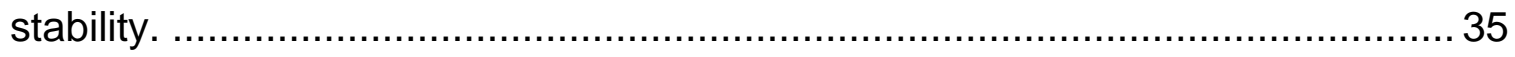

Table 6: Tukey's HSD test result for the foam stability within the chelated

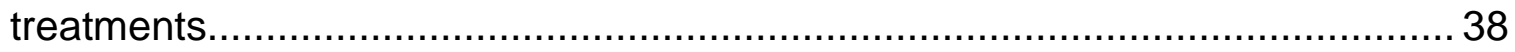

Table 7: Protein Distribution in the Original Solution and the Foam Fraction. .... 42 


\section{LIST OF FIGURES}

Figure 1: Model of casein micelle proposed by Walstra et. al. (2006) ................. 6

Figure 2: Diagram of the structure of foam bubbles proposed by Wilde and

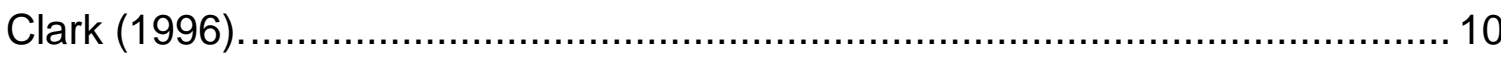

Figure 3: Mechanisms of different foams proposed by Wilde and Clark (1996). 11

Figure 4: Photomicrograph of foam-spray dried milk powder particles by

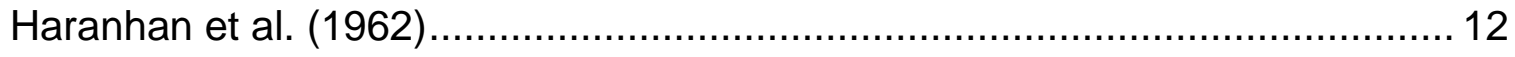

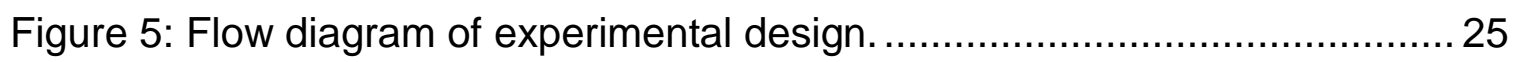

Figure 6: Experimental Setup for Foamability Test....................................... 27

Figure 7: Actual experimental setup for foamability...................................... 28

Figure 8: Histogram of Foamability of Reconstituted SMP chelated by TSC

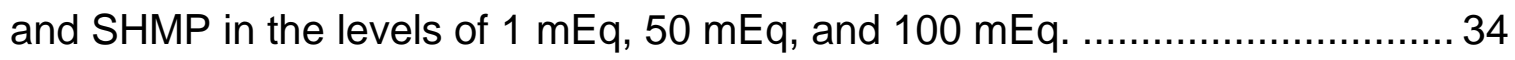

Figure 9: Histogram of Foam Stability of Reconstituted SMP chelated by TSC

and SHMP in the levels of $1 \mathrm{mEq}, 50 \mathrm{mEq}$, and $100 \mathrm{mEq}$. 37 


\section{CHAPTER 1: INTRODUCTION}

Milk foam has been playing an important role in texture development in ice-cream, mousse, whipped topping, meringues as well as coffee (Sharma et al., 2012). With that being noticed, the market sees an increase in the use of foaming properties of milk. Research on the foaming properties date back to the early $20^{\text {th }}$ century, but it was not until the middle of 20th century that this topic attracted people's interests due to the invention and implementing of vacuum drying in milk production; more attention has been paid to this subject because of the expanding market of espresso-style beverages (Huppertz, 2010).

The foaming properties, which includes foamability and foam stability, of milk solution, are determined by a wide variety of factors. Those factors are categorized into intrinsic and extrinsic factors; intrinsic factors include the size of the protein, the hydrophobicity, protein structure flexibility, and extrinsic factors are the surface tension, surface viscosity, surface diffusion and thin film drainage (Wilde and Clark, 1996). Other influential elements were summarized as foaming conditions; i.e., foaming temperature, $\mathrm{pH}$ of the milk, heat treatment, mineral balance, concentration, proteolysis, and appearance of lipids (Huppertz, 2010). Only a limited amount of research has been done for the examination how chelating reactions in milk will change the foaming properties. Kamath et al. (2011) compared chelated reconstituted skim milk by between trisodium phosphate (TSC) and the non-chelated control samples at various temperatures; similar foamability and weaker foam stability were observed in the chelated 
samples at certain temperatures. The comparison of chelated milk and caseinate solutions remained to be examined.

The food industry benefits from caseinate powders because of their good foaming properties. However, the cost of production, limited availability along with other disadvantages restricted its usage. $\beta$-casein in milk is considered as a good material for milk foaming (Fox and McSweeney, 2015). Wilde and Clark (1996) indicated that shelf-life of milk prevented its wide application, while skim milk powder has a much longer storage time due to its low fat and water content. The above opinions see the needs of more studies in the foaming properties of reconstituted skim milk for the replacement of caseinates. With the contradictions on the foaming properties of past research, lack of studies in the comparisons between chelated SMP and caseinates, as well as insufficient studies in the preferential locations of $\alpha_{\mathrm{s}}$-casein, $\beta$-casein, and $\kappa$-casein, more research on the foaming properties of chelated milk should be conducted.

The objective of this research was to determine if chelated SMP can be a good replacement for caseinates on the perspective of foaming properties. 


\section{CHAPTER 2: LITERATURE REVIEW}

2.1. Milk

Generally speaking, cow milk contains $3.3 \%$ of protein, $4.0 \%$ of fat, $4.6 \%$ of lactose, $0.7 \%$ of minerals and the rest of it is water (Walstra et. al, 2006). Different breeds of the producing cow, the milking locations, the feed they are receiving and other factors result in the different values for the composition above. The primary sources of milk are from buffalos, Jersey cattle, and holsteins, varying from geographic locations. Nowadays, farmers get paid for their milk based on the protein proportion in their milk. Milk consists of two kinds of proteins, casein, and whey. They show up in a ratio of about 4:1. Other than macronutrients, bovine milk is a good source of minerals such as calcium, magnesium and zinc, as well as vitamins, for instance, vitamin $A$, vitamin $E$, riboflavin and vitamin B12 (Haug, et al., 2007). The first page of the $20^{\text {th }}$ century saw an increasing interest in fortifying vitamin D into milk (Biancuzzo et al., 2010). O' Donnell et al. (2008) pointed out that fortified milk had a contribution between 40 and $64 \%$ in the total vitamin $D$ intake from foods, and the fortification was efficient enough to improve the vitamin D status in in adults. Table 1 shows the nutrition composition in 1 serving size of whole milk. 
Table 1: Nutrition composition of 1 serving size of whole milk in Standard Reference 28 (USDA, 2015).

\begin{tabular}{|c|c|c|}
\hline Nutrient & Unit & $\begin{array}{c}\text { Value per } 1 \text { Serving } \\
(244 \mathrm{~g})\end{array}$ \\
\hline Total Protein & $\mathrm{g}$ & 7.69 \\
\hline \multicolumn{3}{|l|}{ Amino Acids } \\
\hline Tryptophan & $g$ & 0.098 \\
\hline Threonine & $\mathrm{g}$ & 0.327 \\
\hline Isoleucine & $g$ & 0.398 \\
\hline Leucine & $\mathrm{g}$ & 0.730 \\
\hline Methionine & $g$ & 0.203 \\
\hline Phenylalanine & g & 0.398 \\
\hline Histidine & $\mathrm{g}$ & 0.232 \\
\hline Valine & $g$ & 0.503 \\
\hline Lysine & $g$ & 0.644 \\
\hline Total Lipid & g & 7.93 \\
\hline Fatty acids. total saturated & $\mathrm{g}$ & 4.551 \\
\hline $\begin{array}{l}\text { Fatty acids, total } \\
\text { monounsaturated }\end{array}$ & g & 1.981 \\
\hline $\begin{array}{l}\text { Fatty acids, total poly } \\
\text { unsaturated }\end{array}$ & g & 0.476 \\
\hline Total Carbohydrates & $\mathrm{g}$ & 12.32 \\
\hline Lactose & $\mathrm{g}$ & 12.32 \\
\hline \multicolumn{3}{|l|}{ Vitamins } \\
\hline Riboflavin & $\mathrm{mg}$ & 0.412 \\
\hline Niacin & $\mathrm{mg}$ & 0.217 \\
\hline Folate, total & $\mu \mathrm{g}$ & 12 \\
\hline Vitamin B12 & $\mu g$ & 1.10 \\
\hline Vitamin A & IU & 395 \\
\hline Vitamin E & $\mathrm{mg}$ & 0.17 \\
\hline \multicolumn{3}{|l|}{ Minerals } \\
\hline Calcium & $\mathrm{mg}$ & 276 \\
\hline Magnesium & $\mathrm{mg}$ & 24 \\
\hline Potassium & $\mathrm{mg}$ & 322 \\
\hline
\end{tabular}

2.2. Casein

\subsubsection{Casein Structure}

Casein is the primary protein constituent in milk. It exists in milk in a form of colloidal suspension because of its weak hydrophilicity. According to 
Swaisgood (1993), there are three structures of casein, where the primary structure helped researchers to determine the appearance of $\alpha_{\mathrm{s} 1-\text {-casein, }} \alpha_{\mathrm{s} 2-}$ casein, $\beta$-casein and $\kappa$-casein, researches of secondary structure suggested the potential existence of structural motifs, and its tertiary structure indicated that the hydrophobic domains of the caseins may interact with their secondary structure.

\subsubsection{Casein Models}

Phadungath (2005) summarized the three major types of casein models, which are the coat-core model, internal structure model and subunit model, which is also known as submicelle model. A large casein component is called a casein micelle which is made up of various caseins. Figure 1 is a sketch of a casein micelle. In the subunit model proposed by Walstra et al. (2006), each submicelle contains between 20 and 25 casein molecules; some submicelles may contain 0 to $2 \kappa$-caseins (shown as protruding chains), which shows affinity to water molecules, but about an equal amount of $\alpha_{\mathrm{s}}$-caseins and $\beta$-caseins.

The casein submicelles are held together by the hydrophobic forces between $\alpha_{s}$-caseins and $\beta$-caseins (Walstra et. al, 2006). Horne (2006) pointed out that calcium phosphate is responsible for binding the submicelles together in the milk system. Therefore, the addition of calcium chelating salts into the milk system is expected to take the calcium away and the casein micelle will be broken down into casein submicelles. Zhao and Corredig (2016) claimed that chelators are able to disrupt the structure of casein micelles and in turn the functionality is altered. Caseins are generally considered as good emulsifiers and 
can be foamed easily while its foam stability is limited because of the thick lamella (Fox and McSweeney, 2003).

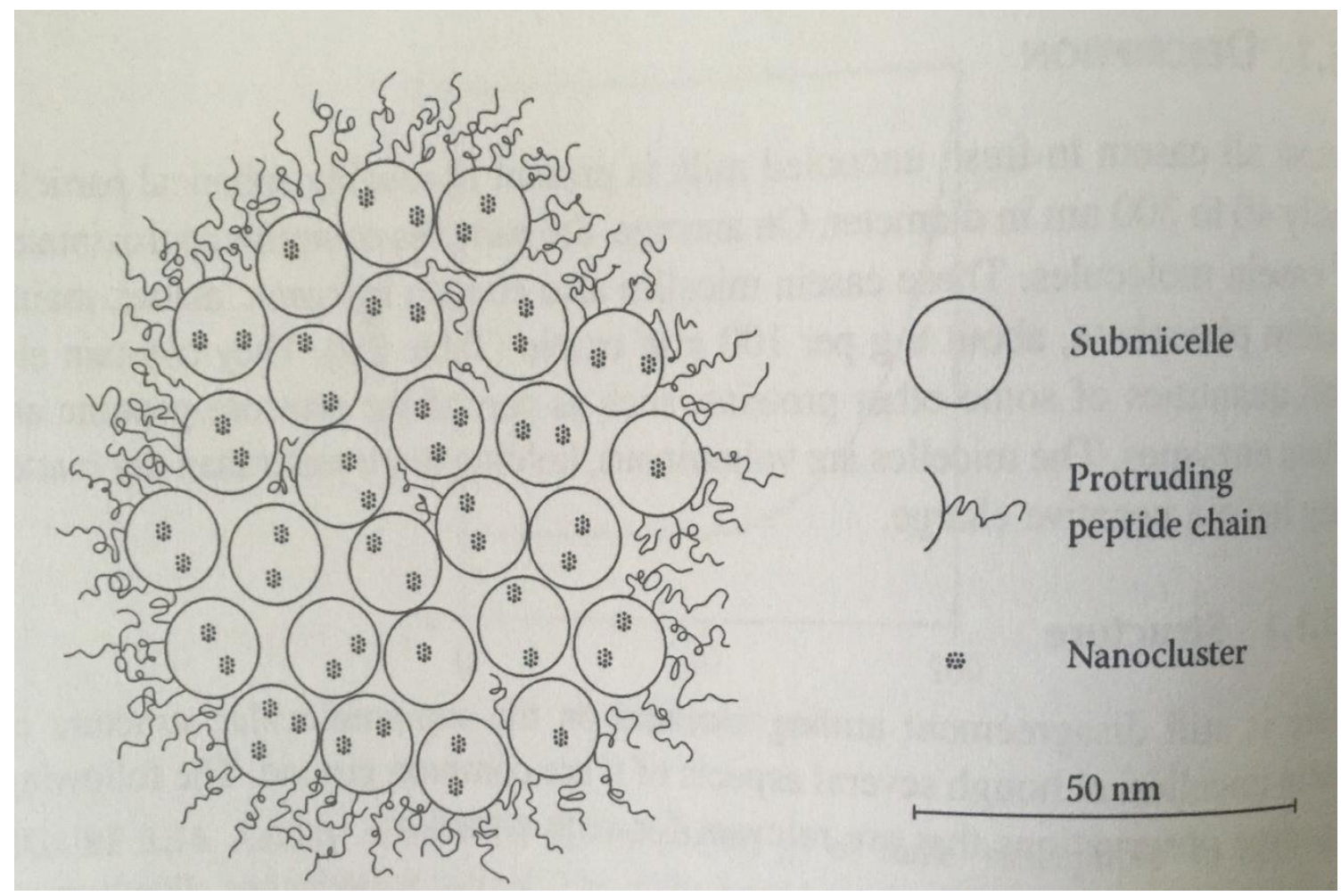

Figure 1: Model of casein micelle proposed by Walstra et. al. (2006)

\subsubsection{Interfacial Properties of Casein}

The interfacial properties of casein have been widely studied because of its benefits in the functionalities in the food and dairy products applications. According to Dickinson (1999), research on the major components of the interfacial materials, which are $\alpha_{\mathrm{s} 1 \text {-casein }}$ and $\beta$-casein, are worthy to be studied because such studies are helpful in finding the relationship between macromolecular structure and the mechanism of biocolloid stabilization, and they will in the end improve the development of dairy ingredients. The open structure, large amounts of apolar amino acids, and distribution of amino acids endow caseins with excellent foaming properties (Fox et al., 2015). Based on the 
experiment conducted by Maldonado-Valderrama et al. (2008), the behavior of milk foams is greatly influenced by the viscoelastic properties of $\beta$-casein.

\subsubsection{Other Uses of Casein}

Not only the food industry values the functions of casein, it has been adjusted for other purposes as well. It was reported that in countries with long history, like Greece, Egypt, Rome and China, casein had been used by craftsmen in making handcrafts for a long time (Sutermeister, 1939). Fox and McSweeney (2003) also mentioned casein in industrial uses like paints making, leather coating as well as rubber manufacturing. The peptides derived through

enzymatic hydrolysis, hydrolysis during microbial fermentation, hydrolysis using enzymes obtained from microorganisms as well as hydrolysis during gastrointestinal digestion can be used in the area of mineral supplementation and antimicrobial peptides (Phelan et al., 2009)

\subsection{Caseinates}

\subsubsection{Composition of Caseinate}

In general, sodium caseinate has a composition of around $40 \% \alpha_{s 1-c a s e i n}$

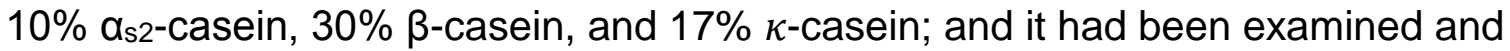
proved that altering the manufacturing process is capable of making changes on the composition, moreover, the compositions of potassium caseinate and calcium caseinate differentiated from the composition of sodium caseinate (Dziuba et al., 1999). This research showed that sodium caseinate extruded from bicarbonate solutions possessed lower contents in $\alpha_{s}$-casein and higher contents in $\beta$-casein, and $\kappa$-casein than the sodium caseinates extruded from hydroxide solutions and 
carbonate solutions. Potassium caseinate appeared to have similar composition compared to sodium caseinate prepared from bicarbonate solutions. $\beta$-casein and $\kappa$-casein contents in calcium caseinate were relatively high.

\subsubsection{Manufacture of Caseinate}

To manufacture caseinates, acidified casein is dewatered and then dissolved in alkali, then the solution is spray dried with a final product of $\mathrm{pH} 6.7$ (Roginski, 2003). For example, the manufacture of potassium caseinate or ammonium caseinate can be fulfilled by the addition of potassium hydroxide or ammonium hydroxide (Fox, 1989).

\subsubsection{Disadvantages of Caseinates}

Caseinates are usually taken advantage in the dairy industry because of high solubility. On the contrary, the disadvantage of it is the high processing cost due to its high viscosity because the caseinate solution can only go up to $20 \%$ concentration before the spray drying process (Fox et al., 2015).

Based on research by Cayen and Baker (1963), large variations of flavor profiles have been detected in sodium caseinates manufactured by different companies; unpleasant properties such as gluey, bitter and oily tastes were also observed.

\subsubsection{Foaming Properties of Caseinates}

In a study done by Walsh et al. (2008), the foams generated by sodium caseinate tend to have better expansion and foam stability. This is because sodium caseinate has excellent surface properties (Sánchez and Patino, 2005), which is very similar to $\beta$-casein (Fox and Mcsweeney, 2015). Sceni and 
Wagner's (2007) study showed that the increasing concentration of sodium caseinate solution comes with an increasing foamability, and their exploration on the foaming properties of caseinates led to another conclusion that Quick Scan method is suggested for the examinations of foams with high concentrations. Another study indicated that foamability was determined by surface tension and $\mathrm{pH}$, while foam stability was influenced by molecular structure and various aggregation behaviors (Marinova et al., 2009). It was also pointed out that foam stability of caseinate solutions correlated with the equilibrium surface pressure, and no coalescence was observed in solutions with low caseinate concentrations (Sánchez and Patino, 2005).

\subsection{Foaming}

\subsubsection{Foaming Principles}

Based on the theory of Wilde and Clark (1996), it is the nature of the airwater interface to form and deform, where the surface tension would increase with the stretching of the thin foam; the foam can be generated with surfactants, proteins, or a combination of surfactants and proteins. A diagram of foam is shown in Figure 2. 


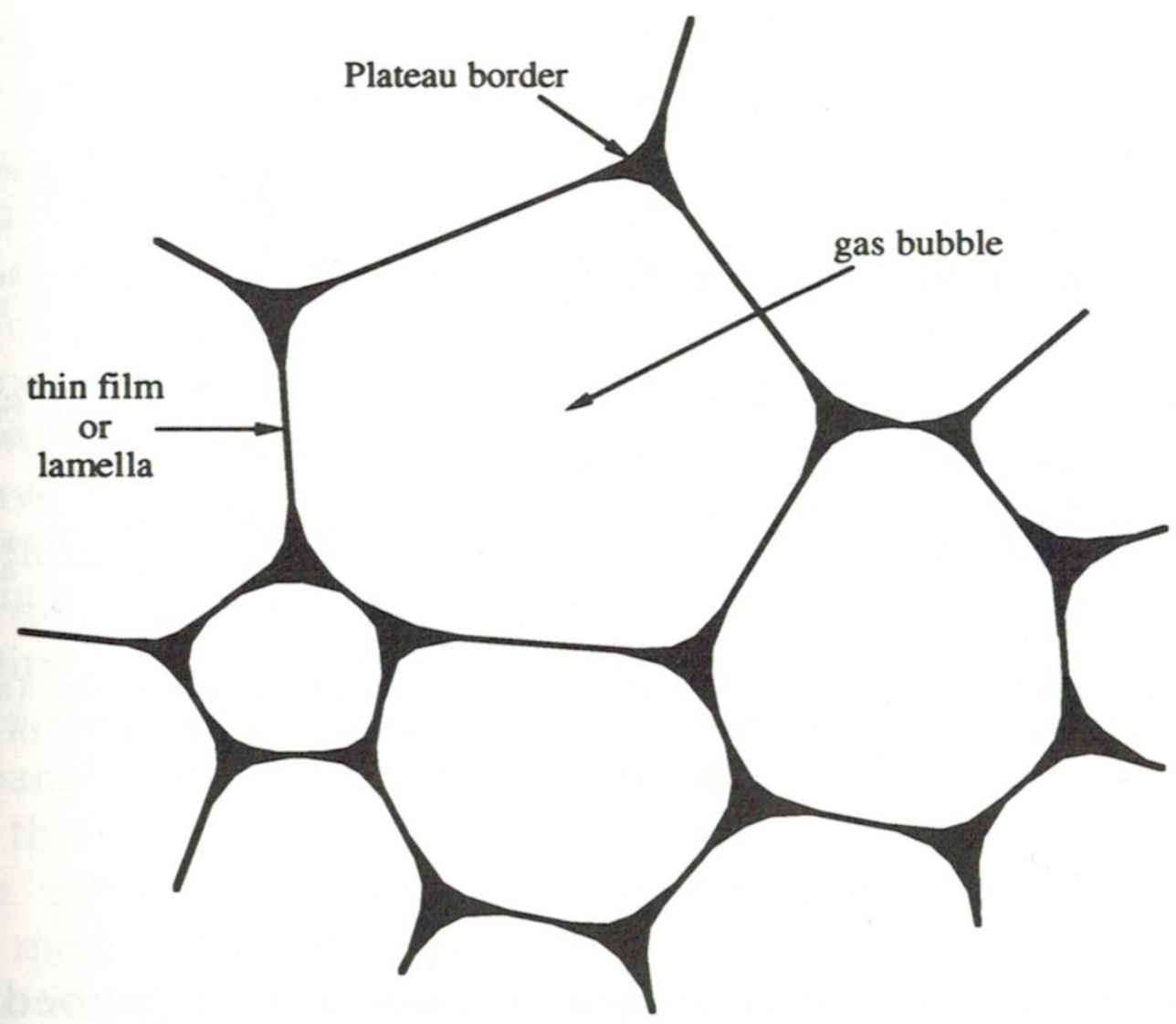

Figure 2: Diagram of the structure of foam bubbles proposed by Wilde and Clark (1996).

The foaming behaviors of foams generated by surfactants and proteins appeared to be different; surfactants-based foams are formed by Marangoni effect where free surfactants will actively replace the diffused ones in the foam, while the proteins will adsorb at the air-water interface with electrostatic, hydrophobic, hydrogen as well as covalent bonds (Wilde and Clark, 1996). A diagram of the mechanisms of surfactant based foam, protein based foam, the combination of surfactant and protein based foam is shown in Figure 3. A foam system containing a mixture of proteins and surfactants is considered to be unstable due to the competition for the sites at the interface and the loss of elasticity of proteins, while the composition of the foam is determined by the 
properties as well as the proportions of the small-molecule surfactants (Rouimi et al., 2005).

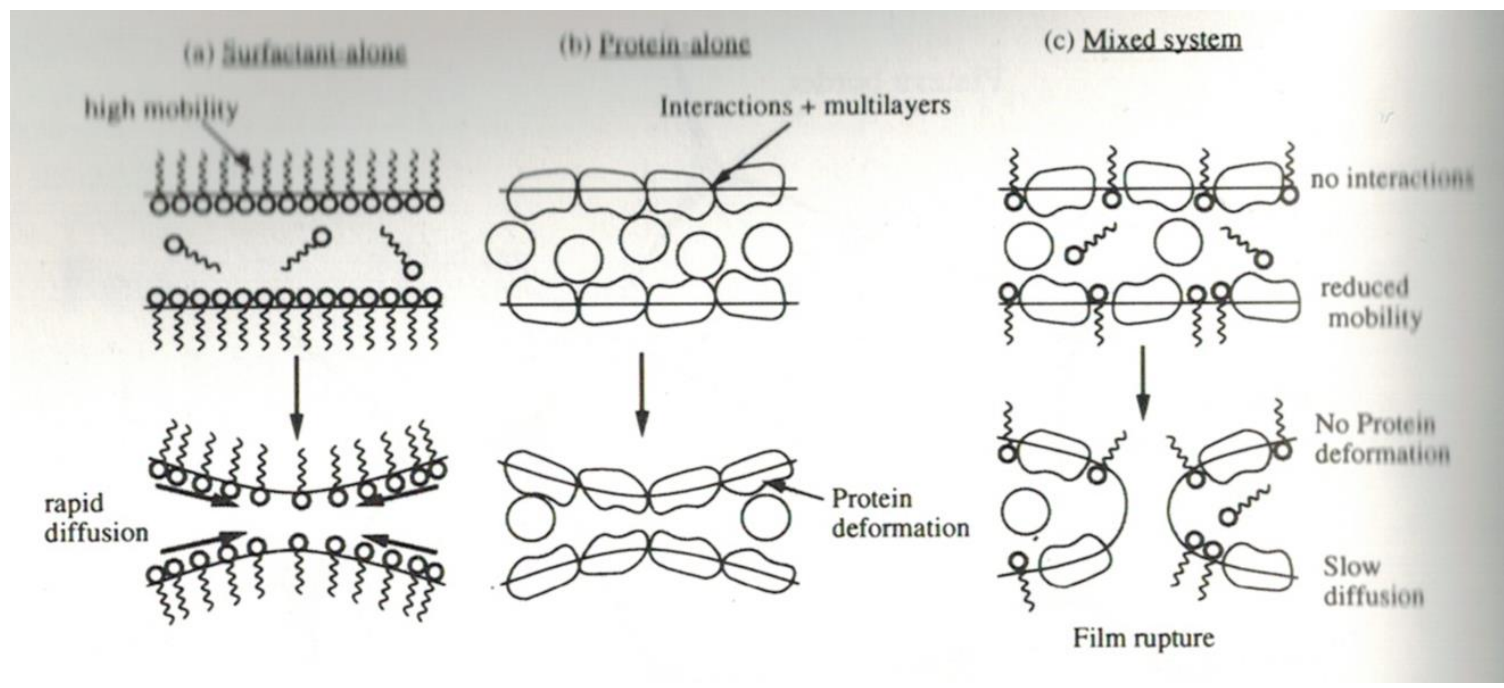

Figure 3: Mechanisms of different foams proposed by Wilde and Clark (1996).

According to Fox et al. (2003), there are three phases for protein film to generate. In the first phase, the proteins are transported to the air-water interface through convection, diffusion, or a combination of these two. The second phase is caused by the electrical charges in the system and the composition of the proteins, specifically the amino acids, is the dominant factor behind it; hydrophobic particles are easier to be adsorbed at the interface. The proteins adsorbed will undergo conformational changes in the third phase; the foam always has a tendency to collapse because the interface is still adsorbing more proteins once formed and the existing proteins on the interface is rearranging themselves and expanding, therefore in the dynamic system, proteins lose their tertiary and maybe secondary structure, which resulted in the conformational change (Fox et al., 2003). 
Milk foam was studied in other forms as well. It had been proved long time ago that milk powder dehydrated through spray drying showed great dispersibility (Hanrahan et al., 1962). A diagram below suggested the particle image of foamspray dried milk powder. The above conclusions were later proved by Berlin et al. (1969) with studies on the water vapor sorption of foam-spray-dried whole milk.

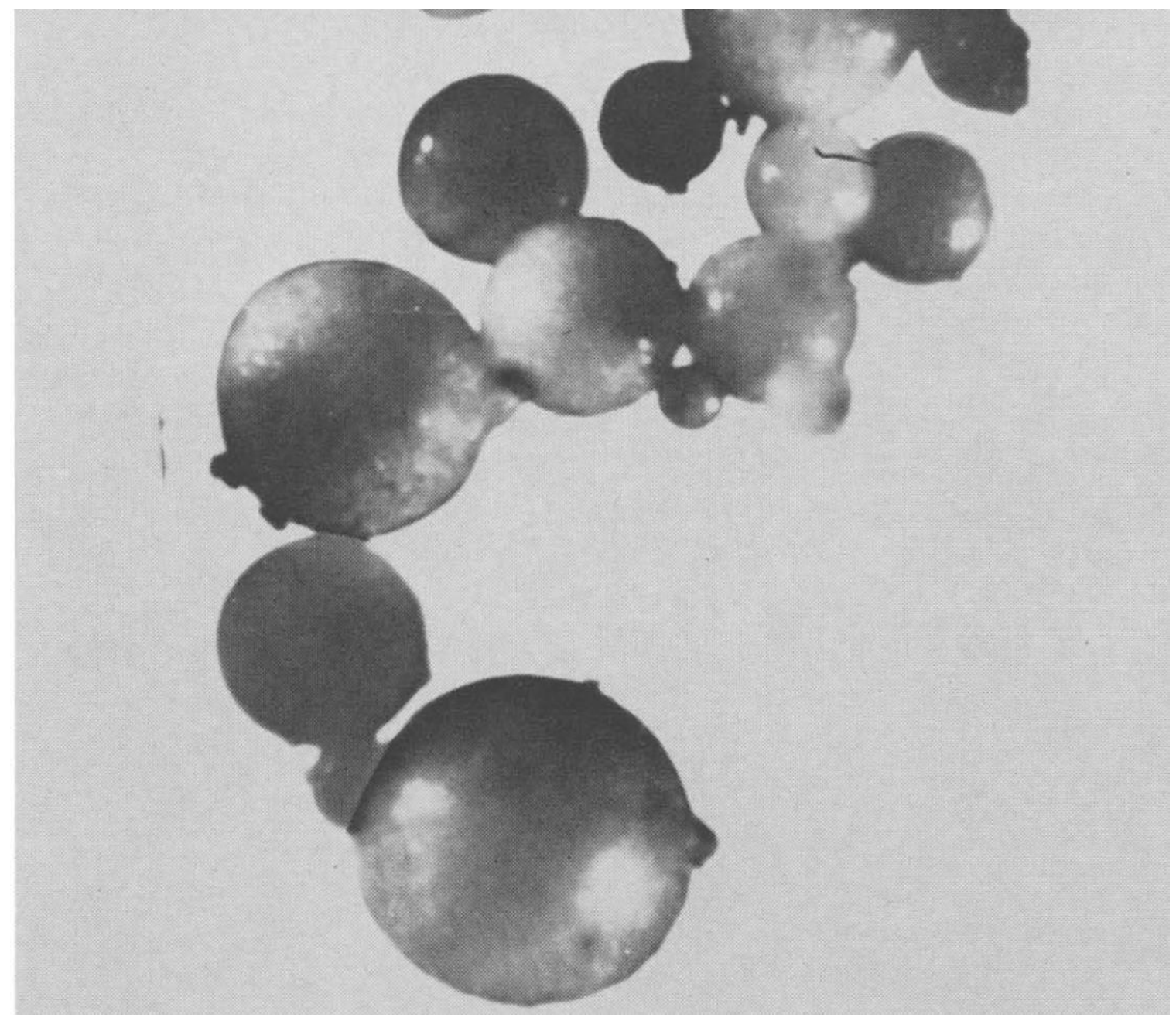

Figure 4: Photomicrograph of foam-spray dried milk powder particles by Haranhan et al. (1962) 


\subsubsection{Milk Foam Composition}

Protein is considered to be excellent foaming agents based on their good adsorption toward the air-water interface, properties of steric stabilization and electrostatic stabilization, and their tendency to form structural coherence (Murray, 2007). It has been proved the that the major composition of milk foam is casein (Kamath et al., 2011).

The above results matched the theory proposed by Fox et al. (2015), that the properties of casein to be an excellent absorbent of air-water due to its open structure, high proportion of apolar amino acid residues and uneven distribution of amino acids. Besides that, $\beta$-casein is the dominant component which has a balanced hydrophilic and hydrophobic properties. On the perspective of foam stability, it is determined by the electric charges, the drainage, and disproportionation of air bubbles. Such factors influence each other and change the system. For example, the electric charge can be altered by the change of $\mathrm{pH}$.

On the isoelectric point, protein will show better hydrophobicity which leading to a better foam stability. Meanwhile, loss of protein hydrophilicity decreases the viscosity of the solution, in which case the foam stability will increase. In the end, there will be more drainage that destabilizes the air-water interface.

\subsubsection{Factors Influencing the Foaming Properties of Milk}

The foaming properties, including foamability and foam stability, are determined by the properties of related surfactants. Intrinsic properties include the size of the protein, the hydrophobicity, and the protein structure flexibility; while surface tension, surface viscosity, surface diffusion and thin film drainage 
consists the extrinsic properties (Wilde and Clark, 1996). However, based on the research conducted in the past few years, other properties of the system have been proved to be influential as well (Huppertz, 2010).

\subsubsection{Influence of Electric Charges on the Foaming Properties of Milk}

An experiment was conducted by Marinova et al. (2009), where researchers adjusted the environment of the solution. Whey protein and sodium caseinate were added into the system, and it was concluded that the ionic strength is directly proportional to the solution foamability. It was proved that sodium caseinate solutions showed the lowest foamability, while whey protein solutions expressed their best foamability.

An investigation carried out by Kamath (2011) concluded that this airserum interface consists of both casein and whey, which disagrees with Mohanty et al. (1988)'s point. Other experiments have been done and proved Marinova's other finding that a high surface elasticity is necessary to sustain the foam for a longer time (Rouimi et al., 2004).

\subsubsection{Influences of Temperature on Milk Foaming Properties}

Oetjen et al. (2014) proved the work of Mohanty et al. (1988) on the aspect of temperature where their work showed that $25^{\circ} \mathrm{C}$ is the minimum temperature for milk to foam, and $40^{\circ} \mathrm{C}$ is the optimum temperature; they also offered valuable data indicating that the fat content has a negative effect for milk to foam. Kamath et al. (2008) explored the influence of temperature on the foaming properties of a variety of milk and concluded that $45^{\circ} \mathrm{C}$ is the most optimum temperature for the skim milk foam stability. 


\subsubsection{Influences of Oil on Milk Foaming Properties}

Kamath and Deeth (2005) ended the prediction that all oil tends to inhibit milk foaming but olive oil improved the foaming process in their experiment. Pilhofer et al. (1994) conducted an experiment in order to examine the behaviors of foamed vegetable oil, milk fat and milk fat fractions, and the result suggested that compared to other kinds of lipids, vegetable oils yielded the lowest drainage while emulsified milk fat was considered to have bad foam stability.

The reason of low stability of emulsified milk fat foam was proposed to be associated with the crystallization activities, and lipid particles were considered to destabilize the air-water interface by penetration the thin films between the air bubbles (Kamath et al.,2008). On the contrary, when foaming temperature was increased above $45^{\circ} \mathrm{C}$, milk fat begins to lose their crystalline state, thus less negative impact on foam stability was observed. However, during the test of halflife, the temperature of the air-water interface would start to drop back to the room temperature where the fat recrystallized within lamella and plateau borders. The researcher considered the recrystallization of milk fat at the air-water interface as a stabilization factor of milk foams.

\subsubsection{Milk Foaming Methods}

Damodaran et al. (1997) proposed methods to measure milk foam and from their point of view, the foamability should be tested by timing how fast the protein adsorb to the air-liquid interface. In contrast, the foam stability can be tested by determining the strength of the intermolecular bonds between the adsorbed protein and the cohesive viscoelastic film. 
Kamath et al. (2011) tested foamability by checking how many millimeters of foam they could achieve out of 50 millimeters of sample solution with an airinjection method Foam stability was measured by recording the time it takes for the foam to reduce to half of its original volume.

The reliability of whipping method combined with overrun and drainage measurement was examined with sodium caseinate, milk protein isolate and whey protein samples. It turned out that the method is simple and capable of detecting differences of foaming properties between the three treatments (Phillips et al., 1987).

\subsubsection{Milk Foam Stability}

Rather than testing the half-life that the foam collapse, Rouimi et al. (2004) used K-12 tensiometer from Krüss to determine the surface tension of the airliquid interface. This is identical to Damodaran et al. (1997) 's test method. The maximum bubble pressure tells the strength of the bonds between the protein and the interface. Foam stability was also explained by stratification phenomenon, which stated that the for a foam to be stable, the radius of the bubble should be in a certain range and the particles size should be smaller than the thickness of the air-water interface so that the particles can be contained. Casein based foam usually has a size of $1 \mu \mathrm{m}$ while the size of each casein submicelle is around $20 \mathrm{~nm}$ (Murray et al., 2004). Previous experimental results showed the the addition of calcium chloride is able to optimize the foam stability of milk since it enhanced the adsorption and aggregation of caseins (Kamath, 2011). 


\subsection{Chelators}

\subsubsection{Functions}

While in milk, chelators are used to remove calcium from solution phase. Calcium phosphate is the compound that binds casein submicelles. Once the calcium is taken out from the system by chelating agents, the submicelles will fall apart. As a consequence, the separated casein submicelles will exist in the liquid as serum caseins. Also, chelators are often used to improve heat stability and increase viscosity in milk (Kort, 2012). Common chelators used in milk are sodium phosphate, polyphosphates, and citrates.

\subsubsection{Influences of Chelators on Dairy Products}

Various calcium chelating salts tend to lead to different chelating levels and outputs in the milk solution. Based on previous study on disodium uridine monophosphate ( $\left.\mathrm{Na}_{2} \mathrm{UMP}\right)$, disodium hydrogen phosphate $\left(\mathrm{Na}_{2} \mathrm{HPO}_{4}\right)$, trisodium citrate, sodium phytate (SP) and sodium hexametaphosphate, the chelating effects can be ranked as: SHMP $>\mathrm{SP}>\mathrm{Na}_{2} \mathrm{HPO}_{4}>\mathrm{Na}_{2} \mathrm{UMP}$ (Kort, 2012). Research that was done by Kaliappan and Lucey (2011) showed that appearance of small amounts of SHMP and disodium phosphate (DSP) will actually increase the amount of calcium phosphate, meaning that such calcium chelating salts are cross-linking with caseins. Both TSC and SHMP are shown to be capable of decreasing the turbidity of milk, but TSC was shown to lower the buffering capacity of milk protein concentrate solution (Mizuno and Lucey, 2005). Furthermore, TSC is often adopted in cheesemaking in order to modify meltability and texture conditions (Mizuno and Lucey, 2005). 


\subsubsection{Influence of Calcium Chelating Salts on the Foaming Properties}

$\beta$-casein is considered to be more surface active compared with intact casein micelles (Zhang and Goff, 2004). Moreover, adding calcium chelating salts was proved to have the effects of increasing the adsorption of $\beta$-casein (Walstra, 1990). However, the experimental results showed that the addition of citrate neither had enhancing effects on the foamability of reconstituted skim milk, nor changed the foam stability under $5{ }^{\circ} \mathrm{C}, 25^{\circ} \mathrm{C}$ and $85^{\circ} \mathrm{C}$; chelated samples showed low foam stability at $45^{\circ} \mathrm{C}$ and $65^{\circ} \mathrm{C}$ (Kamath, 2011). However, the conclusion contradicted with other research when whipping or steam-frothing foaming methods were applied; improvements of foamability and foam stability were contributed from the disassociation of casein micelles (Augustin and Clarke, 2008).

\subsection{Rationale, Objective and Hypothesis}

On the perspective foaming properties of chelated milk, various conclusions have been drawn from different researchers, as some concluded that no changes in foamability can be resulted from the addition of chelators, and foam stability is decreased in this case due the disruption of casein micelles at certain temperatures (Kamath, 2011). On the contrary, the disruption of casein micelles caused by citrates is concluded to be responsible for the improvement of foamability and foam stability, as well as the shift of preferential location of $\beta$ casein from the serum phase to the air-water interface (Augustin et al., 2008).

The objective of this study is to examine the influence of SHMP and TSC at different levels on the foaming properties and preferential locations of $\alpha_{s^{-}}$ 
casein, $\beta$-casein, and $\kappa$-casein of reconstituted SMP. Furthermore, such aspects will be compared with those of sodium caseinate, potassium caseinate, and calcium caseinate.

In this case, the hypothesis of this study is that foamability, foam stability, and the preferential locations of $\alpha$-casein, $\beta$-casein, and $\kappa$-casein will be different across these treatments. 


\section{CHAPTER 3: MATERIALS AND METHODS}

3.1. Chemicals and Ingredients

\subsubsection{Skim Milk Powder}

The skim milk powder (SMP), made from pasteurized milk with low heat treatment spray drying process, was provided by Fonterra, New Zealand. According to the manufacturer, this ingredient has a composition of $54.1 \%$ lactose, $33.4 \%$ protein, $7.9 \%$ minerals, $3.8 \%$ moisture and $0.8 \%$ fat.

\subsubsection{Sodium Caseinate}

The sodium caseinate powder was obtained from Erie Foods International, Inc. (Erie, Illinois). According to the manufacturer, this ingredient has a composition of $94.1 \%$ protein, and $4.1 \%$ moisture.

\subsubsection{Potassium Caseinate}

The potassium caseinate was also provided by Erie Foods International, Inc. (Erie, Illinois). According to the manufacturer, this ingredient has a composition of $97.4 \%$ protein and $4.9 \%$ moisture.

\subsubsection{Calcium Caseinate}

The calcium casein was obtained from Erie Foods International, Inc. (Erie, Illinois). According to the manufacturer, this ingredient has a composition of $94.4 \%$ protein and $3.7 \%$ moisture.

\subsubsection{Sodium Citrate Dihydrate}

Tate \&. Lyle (Decatur, IL) provided the sodium citrate dehydrate powder. According to the manufacturer, this ingredient has a composition of sodium citrate dehydrate and 11 to $13 \%$ moisture content. 


\subsubsection{Sodium Hexametaphosphate}

The sodium hexametaphosphate powder was obtained from ICL Performance Products LP (St. Louis, MO). According to this company, the composition of this ingredient was $\mathrm{P}_{2} \mathrm{O}_{5}$ between $62.8 \%$ and $64.5 \%$ and $0.05 \%$ insoluble.

\subsubsection{Hydrochloride Acid}

$1 \mathrm{~N}$ hydrochloride acid $(\mathrm{HCl})$ was purchased from Fisher Scientific (Waltham, MA).

\subsection{Standardization}

The milk was reconstituted at a $10 \%$ weight by weight concentration. The concentration of caseinate solution was adjusted based on their specifications so that the all the samples will have the same casein level. The casein content of 10\% SMP was determined first with a Rapid Method for Determination of Milk Casein Content by Infrared Analysis (Barbano and Dellavalle, 1987) with certain modifications. Detailed procedures are described below:

1. 150 grams of reconstituted SMP were made with the addition of 15 grams of SMP into 135 grams of deionized water. The solution was mixed with a stirring bar under room temperature for 30 minutes.

2. $25 \mathrm{~mL}$ of the solution were heated to $40^{\circ} \mathrm{C}$ and scanned with a FOSS Milkoscan (Denmark) for protein quantification. 
3. $100 \mathrm{~mL}$ of the solution were transferred into a glass beaker for casein quantification. The solution was placed in a water bath at $40^{\circ} \mathrm{C}$ for 10 minutes.

4. $\mathrm{pH}$ of the heated milk was adjusted to 4.6 with $8 \mathrm{M}$ phosphoric acid.

5. The solution was swirled gently and then heated at $40^{\circ} \mathrm{C}$ for another 10 minutes.

6. The product was filtered through a Whatman \#1 filter paper (Catalog Number: 1541-150, GE Healthcare Life Sciences), and only the filtrate was kept.

7. The filtrate was then purified with a Whatman \#42 filter paper (Catalog Number: 1442-110). A clear solution was achieved at this step.

8. $25 \mathrm{~mL}$ of the clear solution was then heated to $40^{\circ} \mathrm{C}$ for FOSS Milkoscan $\mathrm{FT}^{\mathrm{TM}} 2$ (Eden Prairie, MN) testing.

9. The concentration of casein in the original solution was calculated by the difference of total protein level in the 2 solutions.

3.3. Sample Preparation

\subsubsection{Chelated SMP Samples}

$10 \%(\mathrm{Wt} / \mathrm{Wt})$ SMP solution was reconstituted by mixing 6 grams of SMP into 54 grams of a combination of deionized water and sodium azide. Sodium azide was premixed with deionized water for reconstitution in order to eliminate 
microorganism growth. Chelators, which are SHMP and TSC were added in various amounts and mixed for another 30 minutes. Detailed amounts of ingredients needed are stated in the Table 2. The samples were then stored in a refrigerator set at $4^{\circ} \mathrm{C}$ overnight to ensure an entire chelation process. The next morning, samples were warmed back to room temperature. $\mathrm{pH}$ was adjusted between 6.65 and 6.70 with the addition of $1 \mathrm{~N}$ hydrochloride acid drop-wise. The $\mathrm{pH}$ was monitored with a $\mathrm{pH}$ meter (Orion 2 Star, Thermo Scientific). The samples were stirred for 1 hour so that the system reaches equilibrium. $\mathrm{pH}$ was checked and adjusted if necessary at this point.

Table 2: Amounts of SMP, Chelator and Deionized water in each experimental sample.

\begin{tabular}{|c|c|c|c|}
\hline Chelators & SMP $(\mathrm{g})$ & Chelator $(\mathrm{g})$ & Deionized Water \\
\hline $1 \mathrm{mEq}$ TSC & 6.0 & 0.0222 & 53.9478 \\
\hline $50 \mathrm{mEq}$ TSC & 6.0 & 1.0998 & 52.8702 \\
\hline $100 \mathrm{mEq}$ TSC & 6.0 & 2.2002 & 51.5676 \\
\hline $1 \mathrm{mEq}$ SHMP & 6.0 & 0.0054 & 53.9646 \\
\hline $50 \mathrm{mEq}$ SHMP & 6.0 & 0.2580 & 53.7120 \\
\hline $100 \mathrm{mEq}$ SHMP & 6.0 & 0.5160 & 53.4540 \\
\hline
\end{tabular}

\subsubsection{Caseinate Samples}

The sodium caseinate, potassium caseinate, and calcium caseinate solutions were prepared by mixing caseinate powders and deionized water as the table below so that the casein level is controlled at $3.1657 \%$. The mixtures were set for 1 hour before the $\mathrm{pH}$ adjustment to between 6.65 and 6.70. The $\mathrm{pH}$ 
adjustment procedure was the same as above. Samples were prepared on the day of the test.

Table 3: Composition of caseinate samples.

\begin{tabular}{|c|c|c|}
\hline & Caseinates $(\mathrm{g})$ & Deionized Water $(\mathrm{g})$ \\
\hline Sodium Caseinate & 1.7662 & 50.7075 \\
\hline Potassium Caseinate & 1.7064 & 50.7674 \\
\hline Calcium Caseinate & 1.7605 & 50.7132 \\
\hline
\end{tabular}

3.4. Experimental Design and Analysis

The aim of this experiment was to compare the foamability, foam stability and foam composition of chelated 10\% (Wt/Wt) reconstituted SMP and reconstituted caseinate solutions. The null hypothesis was that there is no detectable difference in foamability, foam stability and foam composition across all treatments. The 9 treatments in this experiment, containing 6 reconstituted SMP treatments treated with a combination of chelator types (TSC or SHMP) and chelator levels ( $1 \mathrm{mEq}, 50 \mathrm{mEq}$ and $100 \mathrm{mEq})$. Such treatments are compared with reconstituted sodium caseinate, potassium caseinate, and calcium caseinate. There were 5 replicates for each treatment in the foamability and foam stability test, and 3 replicate for each treatment for the foam composition test. The experimental design is summarized in Figure 5. All experimental units were prepared and conducted with a randomized order structured with $\mathrm{JMP}^{\circledR}$ software. The retrieved data was analyzed through Analysis of Variance (ANOVA). Each explanatory variable was treated individually and neither factorial design nor blocking factor was used because caseinates were categorized differently 
compared to TSC and SHMP treatments. Tukey's HSD test was conducted once a significant $p$-value was detected in order to compare treatments' outputs.

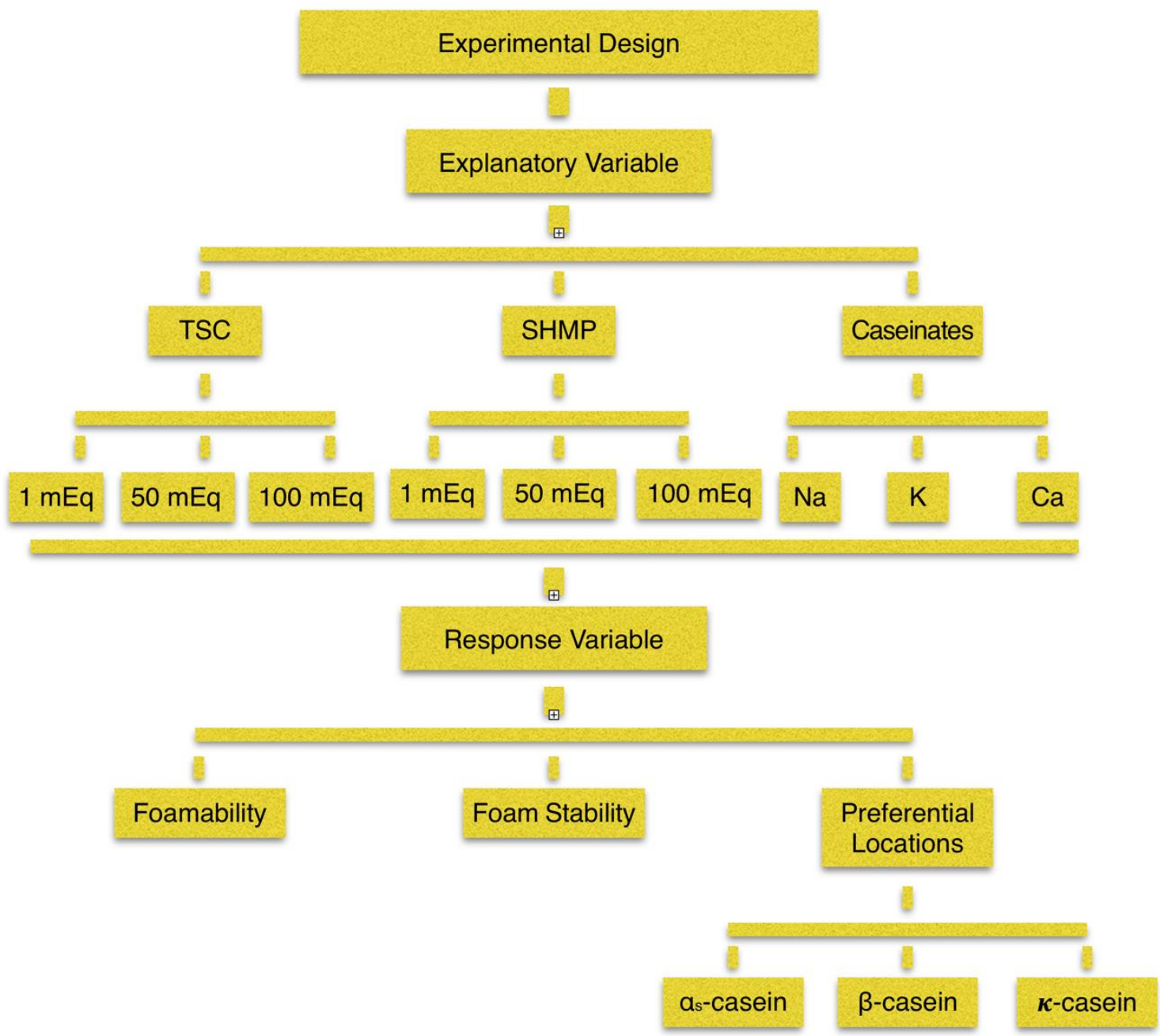

Figure 5: Flow diagram of experimental design.

\subsection{Foamability}

The experimental setup for foamability was from Kamath et al. (2008) with certain adjustments and modifications. The foam was generated with an airinjection method. $50 \mathrm{~mL}$ of each treatment was measured and transferred into a $250 \mathrm{~mL}$ graduate cylinder (No. 70024, Pyrex Vista). A flowmeter (Item Number: 
EW-32460-40, Cole-Parmer) was used to monitor and control the flow rate at 0.3 LPM. The pressure gauge controlled the air pressure between 0.34 and 0.40 psi. A compressed air tank worked as the air supply. A filter tube with $10 \mathrm{MM}$ diameter and type C porosity size (Item Number: 7200-26, Ace Glass) was responsible for forming small bubbles that in the end generate the foam. $\mathrm{A}$ diagram of the experimental setup is seen below (Figure 6). The actual experimental setup for foamability test is shown in Figure 7.

Foamability was expressed as the volume of foam generated after 18 seconds of air injection and can be calculated by the equation below:

$$
\mathrm{Vf}=\mathrm{V}-\mathrm{Vh}
$$

where $\mathrm{V}$ is the reading of the total volume right after the foaming process, Vh represents the volume of the liquid portion. 


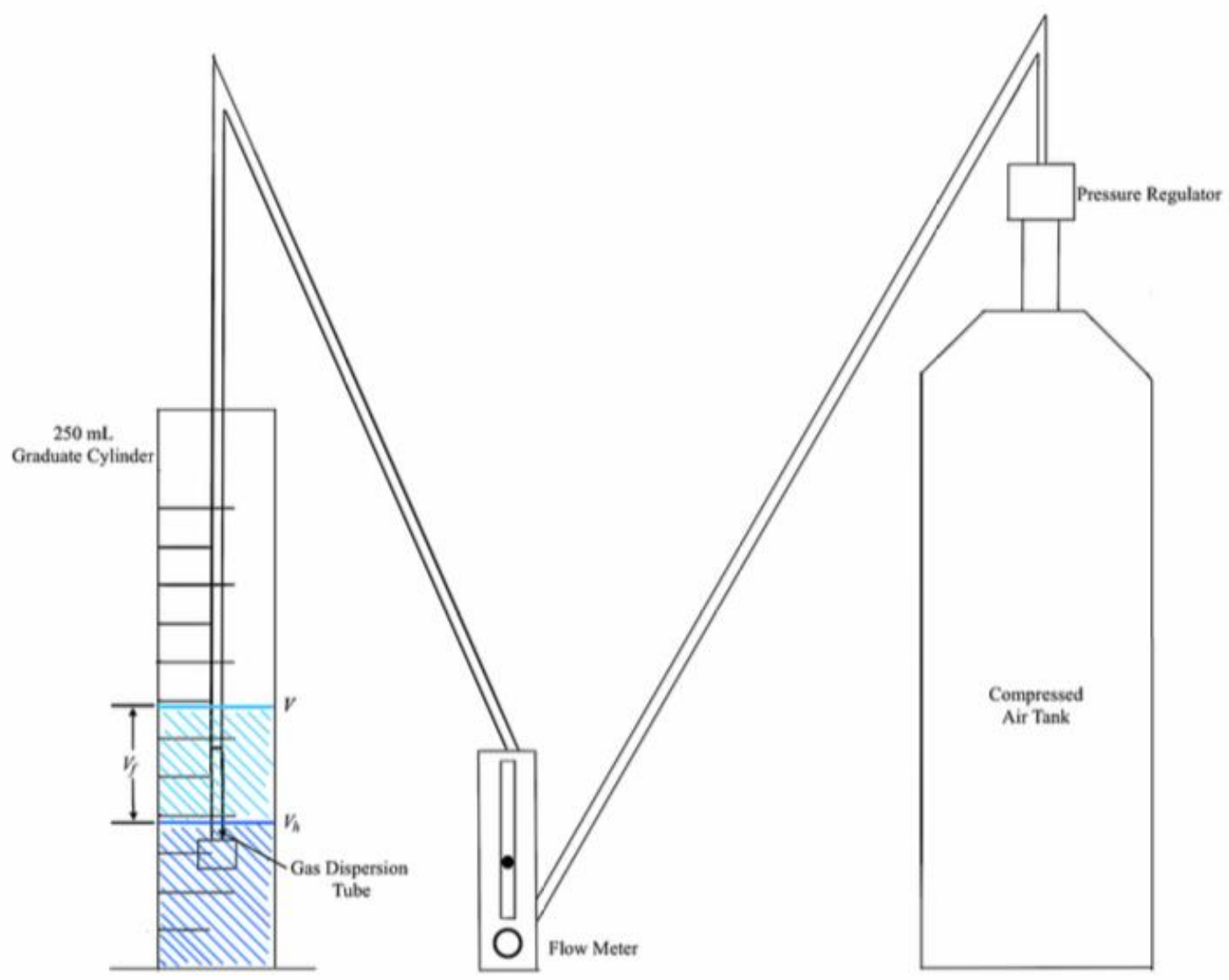

Figure 6: Experimental Setup for Foamability Test.

\subsection{Foam Stability}

Foam stability was analyzed by the half-life method. It was expressed by the minutes it takes for the half volume of the foam to collapse. The foam stability test was conducted at room temperature. 


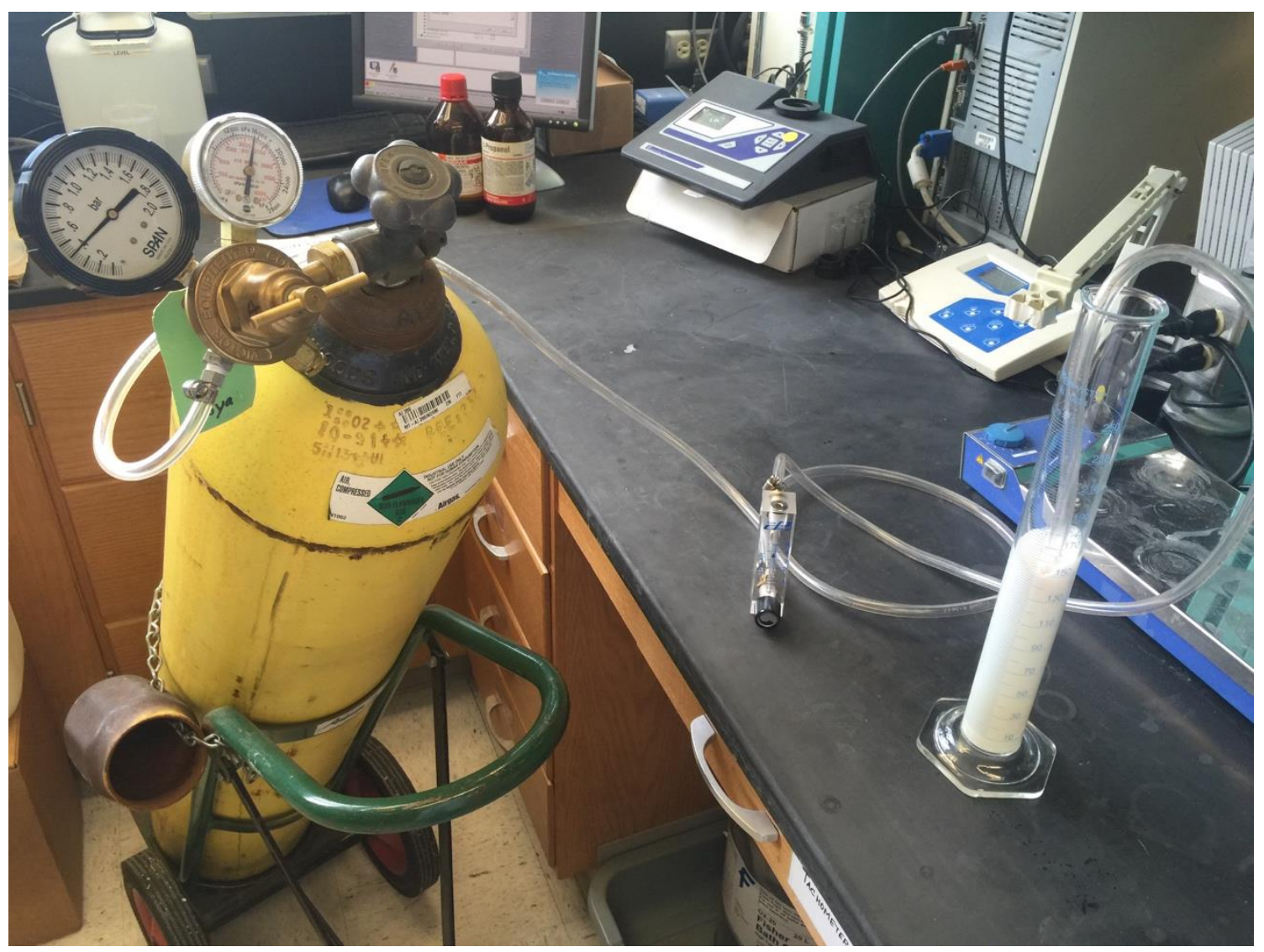

Figure 7: Actual experimental setup for foamability.

\subsection{Gel Electrophoresis}

Sodium dodecyl sulfate polyacrylamide gel electrophoresis (SDS-PAGE) was used to detect and quantify the specific protein that made up of the foam. The Laemmli SDS-PAGE analysis method was refered from Bio-Rad MiniProtean III manual (Bio-Rad, Richmond, CA) with modifications based on the exact conditions of our laboratory. The treatments before foaming and the foam were diluted by 10 times with sample buffer for this analysis. The foam was left overnight in a refrigerator at $4 \stackrel{\circ}{\circ}$ for full collapse, because it may take hours for the foam to totally collapse. Setting the samples in the refrigerator will minimize the possible variations induced by the growth of microorganisms. 
Mini-PROTEIN ${ }^{\circledR}$ TGX $^{\text {TM }}$ PreCast Gels with 12\% Acrylamide (Catalog Number: 4561043DC, Bio-Rad) were mounted into the Mini-PROTEIN ${ }^{\circledR} 2$ Cell. A premixed 10x Tris buffer (Catalog Number: Bio-Rad) was diluted 10 times and poured into the cell. The gel mount was filled first to detect possible leakage. The device was then connected to the power supply (PAC 300, Bio-Rad) and run at $150 \mathrm{~V}$ for 10 minutes. After power disconnection, $1 \mu \mathrm{l}$ of the samples was loaded into wells 1 through 9 and 10 ul of the Precision Plus Protein ${ }^{\text {TM }}$ Standards (Catalog Number: 161-0373) was loaded on well 10. The cell was then reconnected to the power supply and conducted at $150 \mathrm{~V}$ for 30 minutes.

Then, the gel was removed and placed in Coomassie Brilliant Blue R-250 (Catalog Number: 20278, Fisher Scientific) overnight. On the next day, the gel was rinsed with deionized water for four times and soaked in the destain solution for one hour. The process was repeated until a clear background showed up. Gels were stored in the deionized water.

A molecular Imager ${ }^{\circledR}$ was used for gel scan and Quantity One ${ }^{\circledR}$ was adopted for protein analysis. The software was able to generate an Excel ${ }^{\circledR}$ file with data. The composition of $\alpha$-casein, $\beta$-casein and $\kappa$-casein was expressed as percentage content in the loaded protein. 


\section{CHAPTER 4: RESULTS AND DISCUSSIONS}

\subsection{Foamability}

Past research showed that the foamability of milk was associated with the protein particle size (Wilde and Clark, 1996). In this study, skim milk powders treated with higher amount of calcium chelating salts were expected to have better foamability. However, there was no significant difference detected in the foamability of $1 \mathrm{mEq}$ SHMP, $50 \mathrm{mEq}$ SHMP, $100 \mathrm{mEq}$ SHMP, $1 \mathrm{mEq}$ TSC, 50 mEq TSC, $100 \mathrm{mEq}$ TSC, treated SMP, sodium caseinate, potassium caseinate, and calcium caseinate $(p$-value $=0.5301)$. Because of the large $p$-value, it was not necessary to run the post-hoc test because there are no significant differences between the treatments due to the large overall p-value. The histogram below showed that higher concentration of calcium chelating salts did not necessarily lead to better foamability. The mean foamability, standard deviation, and 95\% confidence interval was shown in Table 4.

The expectation of this experiment was that, the addition of TSC and SHMP would improve the foaming properties of reconstituted SMP. According to previous studies, caseins should be more available for the air-water interface with the appearance of calcium chelating salts (Augustin and Clarke, 2008). Kamath et al. (2011), also stated that calcium-chelating agents would enhance the adsorption of $\beta$-casein to the air-water interface. Sodium caseinate reconstituted solution was stated to have the best foamability (Mohanty et al., 1988). The output of this experiment showed that there were no significant differences between the caseinate solutions and the chelated samples. The 
results can be predicted because caseinate solutions have been shown to have good foaming properties (Monhanty et al., 1988) and chelated SMP will have better foamability compared to non-chelated SMP samples (Augustin et al., 2008). These results suggest that the addition of calcium chelating salts increased the foamability of reconstituted SMP. This may be due to the dissociation of casein micelles under the influence of calcium chelating salts, making $\alpha_{s}$-casein and $\beta$-casein more available for the air-water interface.

However, the SMP samples treated with higher amount of calcium chelating salts were expected to have better foaming properties compared to the ones treated with $1 \mathrm{mEq}$. The output of the analysis could not confirm the assumption. A large variance of foamability within the same treatment caused a violation of the equal variance assumption which could be the factor that led to the failure of detecting possible significant differences.

Based on the statistical analysis, it turned out that the difference between the highest and the lowest means should be at least 17.5260 in order to achieve a significant p-value with the current root mean square error of 6.5192 .

Due to the lack of comparison with a control reconstituted SMP treatment, I established another experiment to examine the foamability and foam stability of non-treated SMP, as well as micellar casein solutions. The SMP control treatment has a concentration of $10 \%$ weight by weight, while the concentration of the micellar casein samples was adjusted so that they contain the same amount of casein compared to the other treatments in the original experimental design. In this experiment, each treatment received 6 replicates. Randomization 
of the samples were completed through $\mathrm{JMP}^{\circledR}$. Foamability of each replicate is shown on Appendix 8. The mean foamability of control SMP is $102.667 \mathrm{~mL}$. On average, $94.000 \mathrm{~mL}$ of foam generated out of $50 \mathrm{~mL}$ of micellar casein solution. The 2-sample t-test analysis result showed that the foamability of the control SMP treatment is significantly better compared to the micellar casein solutions (p-value $<0.05)$. Detailed statistical analysis by Minitab Express ${ }^{\circledR}$ is shown on Appendix 9. The difference can be explained by some unique factors of micellar casein solutions. Besides, whey protein was proved to be constituting around $20 \%$ in total protein level of the foam by Kamath et al. (2011) and this study. Both micellar casein and caseinate treatments do not contain any whey protein. Since casein in this solution existed as a whole micelle form, the size of the protein is too large, making it more difficult to be transported to the air-water interface. This matched with Wilde and Clark (1996)'s opinion that proteins in smaller sizes are more optimistic for foamability. Also, the surface-active caseins are trapped in the internal parts of the casein micelle based on the casein submicelle model (Phadungath, 2005). This prohibited those proteins to express their interfacial properties. Due to the disruption of casein micelles with chelators or acidification process during production, this may also have explained the reason that the mean foamability of micellar caseins is smaller when compared with caseinates and chelated SMP. However, since these are two separate experiments, statistical comparisons cannot be conducted.

Table 4: Mean value, standard deviation and $95 \%$ confidence interval of foamability.

\begin{tabular}{|c|c|c|c|}
\hline Factors & Mean & $\begin{array}{c}\text { Standard } \\
\text { Error }\end{array}$ & $\begin{array}{c}\text { 95\% Confidence } \\
\text { Interval }\end{array}$ \\
\hline
\end{tabular}




\begin{tabular}{|c|c|c|c|}
\hline & $\begin{array}{c}\text { Foamability } \\
(\mathrm{mL})\end{array}$ & & \\
\hline Calcium Caseinate & 96.6 & 3.20 & $(90.687,102.513)$ \\
\hline Potassium Caseinate & 103.8 & 3.89 & $(97.887,109.713)$ \\
\hline Sodium Caseinate & 102.6 & 5.02 & $(96.687,108.513)$ \\
\hline $1 \mathrm{mEq}$ SHMP & 105.4 & 0.51 & $(99.4871,111.3129)$ \\
\hline $50 \mathrm{mEq} \mathrm{SHMP}$ & 106.6 & 2.60 & $(100.687,112.513)$ \\
\hline $100 \mathrm{mEq}$ SHMP & 102.4 & 0.75 & $(96.4871,108.3129)$ \\
\hline $1 \mathrm{mEq}$ TSC & 102.8 & 0.86 & $(96.8871,108.7129)$ \\
\hline $50 \mathrm{mEq}$ TSC & 102.6 & 3.87 & $(96.687,108.513)$ \\
\hline $100 \mathrm{mEq}$ TSC & 102.6 & 1.63 & $(96.687,108.513)$ \\
\hline
\end{tabular}

\subsection{Effects of Calcium Chelating Salts on Foamability}

The data of individual chelators and their usage levels were examined individually. Two-way ANOVA was conducted to treat the chelator type (TSC and SHMP), their levels ( $1 \mathrm{mEq}, 50 \mathrm{mEq}$, and $100 \mathrm{mEq}$ ), and the interaction between the chelator type and level as explanatory variables while the foamability was used as the response variable. The overall p-value was 0.5942 . Therefore, there was not enough evidence to convince us that the foamability of chelated SMP at the three chelator concentration levels differed significantly. There was no need for us to conduct any Post-hoc tests. Figure 8 expressed the foamability of all six treatments. The trend indicated that reconstituted SMP treated with $1 \mathrm{mEq}$ and $50 \mathrm{mEq}$ of SHMP had better foamability compared to the ones treated with TSC. But again, the assumption was based on the mean values, and no significant differences were observed in foamability among the nine treatments. 


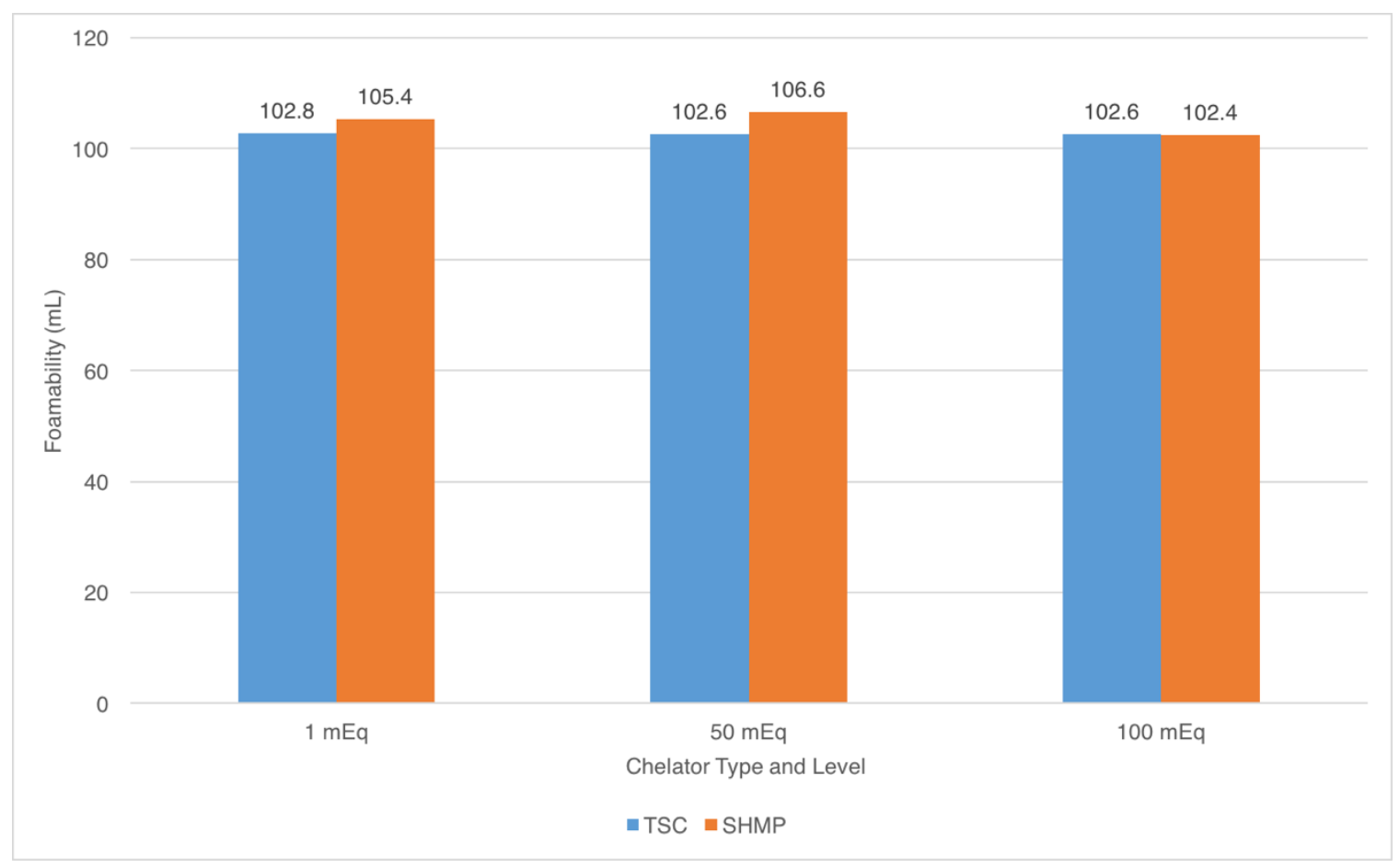

Figure 8: Histogram of Foamability of Reconstituted SMP chelated by TSC and SHMP in the levels of $1 \mathrm{mEq}, 50 \mathrm{mEq}$, and $100 \mathrm{mEq}$.

A maximum difference in mean of 11.76 is needed to detect significant differences based on root mean square error of 4.649373 . The study published by Kamath et al. (2011) showed that the difference in foamability between the chelated SMP with 5mM TSC and the control sample is close to 11.76. Such comparisons may suggest that if standard deviations are controlled to a degree around 1.7, or larger differences were observed in the mean differences between the treatments, it is very likely for us to obtain a significant $p$-value.

\subsection{Foam stability}

A previous study showed that the addition of calcium chelating salts will result in a decrease in foam stability (Kamath et al., 2008). Statistical analysis of this experiment indicated significant differences across the treatments ( $p$-value $<$ 
0.0001). Tukey's HSD was conducted in order to detect the differences between the samples. It appeared that samples treated with the least amounts of calcium chelating salts ( $1 \mathrm{mEq}$ SHMP and $1 \mathrm{mEq}$ TSC) showed the best foaming properties. However, there were no significant differences detected between these two treatments. On the other hand, the rest of the treatments had significant lower foam stability compared to $1 \mathrm{mEq}$ SHMP and $1 \mathrm{mEq}$ TSC, but there were no significant differences between these two treatments. The mean foam stability, standard deviation and $95 \%$ confidence interval are shown in Table 5.

Table 5: Mean value, standard deviation and 95\% confidence interval of foam stability.

\begin{tabular}{|c|c|c|c|c|}
\hline Factor & $\mathrm{N}$ & $\begin{array}{c}\text { Mean } \\
\text { Foam Stability } \\
\text { (min.) }\end{array}$ & $\begin{array}{l}\text { Standard } \\
\text { Error }\end{array}$ & $\begin{array}{l}\text { 95\% Confidence } \\
\text { Interval }\end{array}$ \\
\hline $\begin{array}{c}\text { Calcium } \\
\text { Caseinate }^{b}\end{array}$ & 5 & 3.4000 & 0.24 & $(-0.4906,7.2906)$ \\
\hline $\begin{array}{l}\text { Potassium } \\
\text { Caseinate }^{b}\end{array}$ & 5 & 11.200 & 1.43 & $(7.309,15.091)$ \\
\hline $\begin{array}{c}\text { Sodium } \\
\text { Caseinate }^{\mathrm{b}}\end{array}$ & 5 & 3.4000 & 0.24 & $(-0.4906,7.2906)$ \\
\hline $1 \mathrm{mEq}$ SHMPa & 5 & 64.000 & 2.65 & $(60.109,67.891)$ \\
\hline 50 mEq SHMPb & 5 & 9.000 & 0.63 & $(5.1094,12.8906)$ \\
\hline $100 \mathrm{mEq}$ SHMPb & 5 & 9.2000 & 0.80 & $(5.3094,13.0906)$ \\
\hline $1 \mathrm{mEq}$ TSC $^{\mathrm{a}}$ & 5 & 52.200 & 4.58 & $(48.309,56.091)$ \\
\hline $50 \mathrm{mEq} \mathrm{TSC}^{\mathrm{b}}$ & 5 & 10.2000 & 0.97 & $(6.3094,14.0906)$ \\
\hline $100 \mathrm{mEq}$ TSC $\mathrm{c}^{\mathrm{b}}$ & 5 & 10.200 & 1.02 & $(6.309,14.091)$ \\
\hline
\end{tabular}

* Samples sharing the same letter do not have a statistically significant difference in foam staibility.

Caseinate was considered and proved to have good foam stability (Mohanty et al., 1988). Past research fulfilled by Kamath et al. (2011), asserted that chelating reconstituted SMP would decrease the foam stability because $\beta$ - 
casein would have less capability to aggregate on the interface. Huppertz (2010) summarized the past works and determined that calcium chelators would actually improve the foamability. The above standpoints contradicted each other. Based on the analysis of this experiment, SMP samples with $1 \mathrm{mEq}$ chelator concentration had the best foam stability among all the chelated treatments, and was significantly better compared to other treatments. The addition of large amounts of SMP seemed to decrease the foamability. This study confirmed with the opinion that the addition of calcium chelating salts can decrease the foam stability. This result matched with Kamath et al.'s (2011) opinion but contradicted with Augustin et al.'s (2008) findings. The variances might be caused by the different sample preparations, foaming methods and possibly other factors. In Augustin et al.'s (2008) experiment, the calcium chelating salts were added prior to the spray drying process while in this experiment, calcium chelating salts were added right after the SMP reconstitution process. Other than that, those caseinate solutions had very low foam stability and contradicted with Mohanty et al.'s (1988) experimental result. However, pH of caseinate solution was adjusted to different levels. Wilde and Clark (1996) pointed out that the electric charges in the sample environment play an important role in determining foam stability.

\subsection{Effects of Calcium Chelating Salts on Foam Stability}

Another ANOVA statistical test was conducted to examine the chelated samples alone for foam stability. The chelator type, their levels and the interaction were the explanatory variables. The interaction was treated as the combination of the chelator type and the chelator level, and analyzed as a factor 
along with these two main effects. Examining the interaction is important because a significant interaction represents the simultaneous influence of two variables. The overall $p$-value of this analysis was less than 0.0001 , indicating that significant differences in foam stability existed within the six treatments. Hence, the individual test effects were examined. The results showed that the interaction between the chelator type and chelator level had a p-value of 0.0118 . There is strong evidence to convince us that the combination of chelator type and chelator level had resulted in significant differences in the foam stability. The mean half-life of each treatment is shown in Figure 9. In this scenario, it is not necessary for us to look at the main effects.

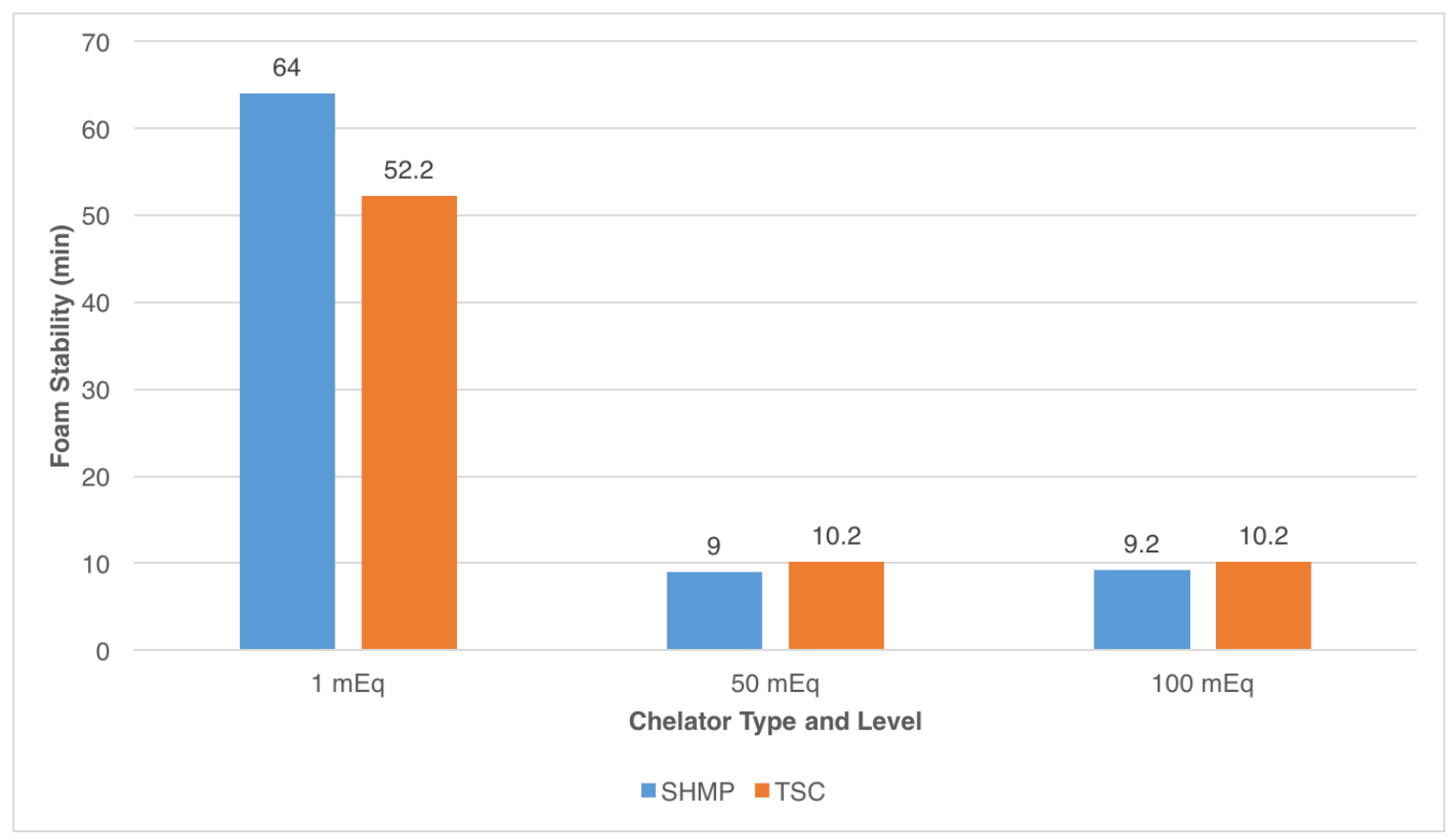

Figure 9: Histogram of Foam Stability of Reconstituted SMP chelated by TSC and SHMP in the levels of $1 \mathrm{mEq}, 50 \mathrm{mEq}$, and $100 \mathrm{mEq}$.

In this case, a Tukey's HSD test was run to determine the detailed significant differences, and these results are shown in Table 6. It appeared that 
reconstituted SMP treated with $1 \mathrm{mEq}$ SHMP samples had significantly stronger foam stability than those treated with $1 \mathrm{mEq}$ TSC. $1 \mathrm{mEq}$ TSC samples had significant stronger foamability compared to the rest of the treatments. No significant differences in foamability were detected within the treatments of 50 mEq TSC, $100 \mathrm{mEq}$ TSC, $50 \mathrm{mEq}$ SHMP and $100 \mathrm{mEq}$ SHMP. It also appears that the samples treated with higher levels of calcium chelating salts had lower foam stability. This result matched with Kamath et al. (2011) 's conclusion that the addition of chelators would lead to a decrease in foam stability. The reason can be explained by Walstra (1990) 's theory that casein micelles will lose stability when being turned into submicelles by taking away the calcium phosphates out of the casein micelles, which worked as bonds that hold casein submicelles together.

Table 6:Tukey's HSD test result for the foam stability within the chelated treatments.

\begin{tabular}{|c|c|c|}
\hline Chelator Type & Level (mEq) & Least Square Mean (min.) \\
\hline SHMP & 1 & $64.00^{\mathrm{a}}$ \\
\hline TSC & 1 & $52.20^{\mathrm{b}}$ \\
\hline TSC & 50 & $10.20^{\mathrm{c}}$ \\
\hline TSC & 100 & $10.20^{\mathrm{c}}$ \\
\hline SHMP & 100 & $9.20^{\mathrm{c}}$ \\
\hline SHMP & 50 & $9.00^{\mathrm{c}}$ \\
\hline
\end{tabular}

* Samples sharing the same letter do not have a statistically significant difference in foam staibility. 
The high mean half-life values shown in $1 \mathrm{mEq}$ TSC and SHMP treatments and low stability in treatments with high amounts of chelators can be resulted from 2 possible reasons. For the first possibility, $1 \mathrm{mEq}$ could be the special chelator concentration to improve foam stability. On the other hand, the addition of calcium chelating salts can only destabilize the foam stability but due to the lack of control SMP treatment, this possibility can not be explored. In the experiment to compare the foam stability between non-treated SMP and micellar casein, non-treated SMP has a mean half-life of 31.5 minutes while foams of micellar casein totally collapsed within 1 minute. Foam stability of non-chelated SMP is significantly higher than the micellar casein solutions ( $p$-value $<0.05)$. Statistical analysis Minitab Express ${ }^{\circledR}$ is shown on Appendix 10. Although the mean half-life of control SMP is higher than the $50 \mathrm{mEq}$ and $100 \mathrm{mEq}$ chelated SMP treatments, it still appeared to be lower than the $1 \mathrm{mEq}$ treatments by around 20 minutes, suggesting that the addition of $1 \mathrm{mEq}$ concentration of SHMP or TSC improved the foam stability. The result partially supported the opinions from Augustin et al. (2008), where they mentioned that a disruption of casein micelles and release of $\beta$-casein can improve the foam stability. The zero half-life of micellar casein based foam can also explain by their theory. The bubble coalescence and disproportionation mechanisms can be detected visually in micellar casein foams, where the lamella was breaking and bubbles were merging. But my study also indicated that the disruption should be maintained to a certain degree for the improvement. A total disruption decreased the ability for the casein micelles to aggregate at the air-water interface (Kamath et al., 2008). 
This is possibly why SMP treated with $50 \mathrm{mEq}$ and $100 \mathrm{mEq}$ chelators showed low foam stability. However, since these are two separated experiments, statistical analysis cannot be conducted.

\subsection{Foam Composition}

Kamath et al. (2011), analysis of the foam composition of reconstituted SMP across several temperatures showed that the foam consisted of around 40\% $\alpha_{s}$-casein, 30\% $\beta$-casein, 10\% $\kappa$-casein, 15\% $\beta$ - lactoglobulin, and 5\% $\alpha$ lactalbumin. However, the researchers did not examine the foam composition of the chelated samples. According to the theory proposed by Augustin et al. (2008), calcium chelating salts are able to dissociate casein micelles and release casein submicelles into the serum. The protein content in the foam was assumed to be higher. The protein composition was expressed as the percentage of protein in the original solution and in the foam. The exact content of as-casein, $\beta$ casein, $\kappa$-casein, $\beta$-lactoglobulin, and $\alpha$-lactalbumin, plus standard deviation from the present study are shown in Table 7. Caseinates were manufactured with casein solutions, therefore, (as expected) there were no bands expressing the existence of any kind of whey protein on the SDS-PAGE gels. The percentage of $\beta$-lactoglobulin and $\alpha$-lactalbumin was marked as not detectable (N.D.). The output of this experiment showed that the foam had an average of $36.06 \%$ ascasein, $34.77 \% \beta$-casein, and $1.42 \% \kappa$-casein. These results are similar to the past research except that there was an increase in the percent $\beta$-casein and decrease in the $\kappa$-casein. This might be the result of the addition of chelators and the involvement of caseinate solutions. 
To statistically analyze the preferential locations of the $\alpha_{s}$-casein, $\beta$ casein, and $\kappa$-casein, the difference of these three kinds of caseins in the original solution have been calculated. ANOVA tests had been conducted in order to determine if significant differences existed. 
Table 7: Protein Distribution in the Original Solution and the Foam Fraction.

\begin{tabular}{|ccccccc|}
\hline & & $\alpha_{s}$-casein & $\beta$-casein & $\kappa$-casein & $\beta$-lactoglobulin & $\alpha$-lactalbumin \\
\hline TSC-1 & Liquid & $37.50 \pm 1.34$ & $35.53 \pm 1.03$ & $1.22 \pm 0.68$ & $9.29 \pm 1.05$ & $1.93 \pm 1.23$ \\
\hline & Foam & $38.15 \pm 1.78$ & $33.88 \pm 2.15$ & $0.74 \pm 0.65$ & $8.24 \pm 2.14$ & $2.60 \pm 2.03$ \\
\hline TSC-2 & Liquid & $35.93 \pm 2.27$ & $34.48 \pm 1.78$ & $0.75 \pm 0.63$ & $9.90 \pm 1.70$ & $5.89 \pm 1.14$ \\
\hline & Foam & $35.44 \pm 1.74$ & $32.42 \pm 1.18$ & $1.39 \pm 0.96$ & $10.47 \pm 2.14$ & $3.86 \pm 1.33$ \\
\hline TSC-3 & Liquid & $32.61 \pm 0.17$ & $30.05 \pm 1.65$ & $1.31 \pm 1.03$ & $13.82 \pm 0.04$ & $7.05 \pm 0.47$ \\
\hline & Foam & $32.03 \pm 0.85$ & $31.64 \pm 1.02$ & $1.67 \pm 0.61$ & $12.82 \pm 0.56$ & $5.70 \pm 0.73$ \\
\hline SHMP-1 & Liquid & $35.65 \pm 2.14$ & $33.86 \pm 2.03$ & $0.54 \pm 0.39$ & $11.32 \pm 2.33$ & $4.26 \pm 2.22$ \\
\hline & Foam & $33.91 \pm 2.44$ & $32.97 \pm 3.08$ & $1.07 \pm 0.80$ & $11.37 \pm 3.90$ & $5.06 \pm 3.10$ \\
\hline SHMP-2 & Liquid & $33.41 \pm 3.39$ & $33.09 \pm 3.39$ & $1.25 \pm 1.49$ & $13.11 \pm 2.33$ & $5.41 \pm 1.98$ \\
\hline & Foam & $32.92 \pm 3.48$ & $31.91 \pm 3.30$ & $1.25 \pm 0.70$ & $12.97 \pm 4.84$ & $4.21 \pm 2.01$ \\
\hline SHMP-3 & Liquid & $34.80 \pm 1.67$ & $34.40 \pm 1.81$ & $2.94 \pm 1.45$ & $10.93 \pm 1.13$ & $3.83 \pm 0.32$ \\
& Foam & $35.32 \pm 2.63$ & $30.95 \pm 2.58$ & $1.26 \pm 0.41$ & $11.25 \pm 4.08$ & $5.72 \pm 2.25$ \\
\hline Na-Cas & Liquid & $38.58 \pm 3.31$ & $36.26 \pm 3.64$ & $1.62 \pm 0.33$ & ND & ND \\
\hline & Foam & $36.08 \pm 6.94$ & $38.77 \pm 0.72$ & $1.40 \pm 1.19$ & ND & ND \\
\hline K-Cas & Liquid & $36.09 \pm 1.37$ & $36.46 \pm 2.16$ & $4.17 \pm 0.21$ & ND & ND \\
\hline & Foam & $38.79 \pm 1.71$ & $38.75 \pm 3.13$ & $1.79 \pm 1.16$ & ND & ND \\
\hline Ca-Cas & Liquid & $39.89 \pm 4.34$ & $37.62 \pm 2.85$ & $2.56 \pm 1.58$ & ND & ND \\
& Foam & $41.88 \pm 1.83$ & $41.65 \pm 3.56$ & $2.24 \pm 0.47$ & ND & ND \\
\hline
\end{tabular}

* TSC-1: 1 mEq TSC; TSC-2: 50 mEq TSC; TSC-3: 100 mEq TSC; SHMP-1: 1 mEq SHMP; SHMP-2: 50 mEq

SHMP; SHMP-3: 100 mEq SHMP; Na-cas: sodium caseinate; K-cas: potassium caseinate; Ca-cas: calcium caseinate. 


\subsection{1. $\alpha_{s}$-casein}

As has been studied by Creamer et al. (1982), as-casein showed hydrophobicity. Hence, it was expected that there would be more as-casein in the milk foam because of its hydrophobicity property. In order to detect the preferential locations of $\alpha_{s}$-casein in all treatments, ANOVA was conducted. The overall $p$-value of this test is 0.7580 . There is not enough evidence for us to detect significant differences between the treatments. The result helped us to conclude that there is no preferential location for the $\alpha_{s}$-casein at the foam.

\subsection{2. $\beta$-casein}

The null hypothesis of this test is that there are no detectable significant differences on the preferential locations of $\beta$-casein while the alternative hypothesis is that significant differences of $\beta$-casein preferential locations between the nine treatments. Based on the studies fulfilled by Lin et al. (1972), the addition of calcium chelating salts is able to release $\beta$-casein into the serum. In this case, an increase in the amount of surface active $\beta$-casein can be expected in the milk foam (Kamath, 2011). In this scenario, $\beta$-casein should be more located in the milk foam, and the case will be apparent in the reconstituted SMP samples treated with higher levels of chelators. The overall p-value of the ANOVA to examine $\beta$-casein content is 0.2196 . There was not sufficient evidence to convince us that there are significant differences between the treatments in the preferential locations of $\beta$-casein among the treatments. Null hypothesis of this test is accepted. It appeared that no differences in the preferential locations of $\beta$-casein in the treatments. For the chelated samples, the 
release of $\beta$-casein from the micelles into the serum did not make more $\beta$-casein adsorb to the air-water interface. The situation may be resulted from the case that $\beta$-caseins released by calcium chelating salts have smaller particle sizes and it make it hard to $\beta$-caseins to aggregate on the interface (Walstra, 1990).

\subsection{3. $\kappa$-casein}

The preferential locations of $\kappa$-casein were expected to be the same since no treatments in this experiment were intended to change any properties of it. And this have been proved by the result of ANOVA with an insignificant $p$-value of 0.1388 . The conclusion is that there were no significant differences in the $\kappa$ casein preferential locations in the treatments. Its preferential locations remained to be the same either the treatments were caseinate solutions or the chelated reconstituted SMP.

\subsection{Overall Discussion}

In conclusion, there is no significant difference detected in foamability between the caseinate solutions and the chelated reconstituted SMP treatments. According to Monhanty et al. (1988), caseinate solutions are believed to have good foaming properties, and the results of the current study may suggest that the addition of calcium chelating salts can boost the foamability of reconstituted SMP.

On foam stability, reconstituted SMP treated with very low levels of chelators showed better foam stability. Statistical analysis pointed out that the presence of high amounts of calcium chelating salts are associated with low foam stability. It was not expected that sodium, calcium and potassium 
caseinates would have very low mean foam stability. These results were in contrast to previous studies (Marinova et al., 2009). One explanation of the inconsistent results can be the differences of the viscosity because the caseinate solutions were prepared at different protein concentrations than the SMP solutions.

Other than the aspects stated above, the preferential locations of the $\alpha_{s^{-}}$ casein, $\beta$-casein, and $\kappa$-casein remained to be the same despite the treatments. Although the addition of calcium chelating salts was able to release $\beta$-caseins (Lin, 1972), they did not result in a larger amount of $\beta$-casein attached to the airwater interface.

In conclusion, the addition of calcium chelating salts may boost the foamability to the same level as the caseinate solutions, and decreased the foam stability. Chelated reconstituted SMP might be a good replacement for caseinates in the perspective of foaming, however, more studies should be done in this area because the foaming properties is dependent on the foaming methods (Huppertz, 2010). 


\section{CHAPTER 5: CONCLUSION AND SIGNIFICANCE OF FINDINGS}

There were no significant differences found in foamability between caseinate solutions and reconstituted SMP treated with calcium chelating salts. It has been proved that the combination of chelators and their levels can change the foam stability. Samples treated with a higher amount of chelators had weaker foam stability. It was found that casein was the major component of the air-water interface. $\alpha_{s}$-casein and $\beta$-casein made up of around $80 \%$ of the protein in the foam. The foam of caseinate solutions had a higher portion of $\beta$-casein. No preferential locations of $\alpha_{\mathrm{s}}$-casein, $\beta$-casein and $\kappa$-casein were detected. The addition of calcium chelating salts may pull up the foamability of reconstituted SMP to the same level as caseinate solutions, but overdosing was shown to decrease the foam stability. 


\section{CHAPTER 6: LIMITATIONS AND DIRECTIONS FOR FUTURE RESEARCH}

Although a good quantity of studies has been done on the foaming properties of caseins, there are some areas that remain to be explored. With the growing demands for the use of such properties from the food industry, as well as the limited amount of work had been done on the interactions between foaming factors, more research needs to be done on the interfacial materials generated from milk solutions. Following research directions are suggested as follows:

1. On the perspective of foamability test, the equal variance assumption was found to be violated due to large standard deviations within the treatments. Before then, a lot of work had been done to yield more uniform outputs. The large variance is now believed to be generated due to the test method. Thus, foamability is recommended to be measured by an overrun method where the liquid should be foamed totally. Meanwhile, whipping rather than air-injection method is suggested.

2. The output of the SDS-PAGE analysis indicated lower amount of $\alpha_{s}$-casein and $\kappa$-casein existed within the caseinate solutions compared to caseinate content determination test results (Dzuiba et al., 1999); if the previous study is valid, it would be not convincing enough to generalize the conclusions of this study into a broader scale. Caseinate powders from various sources should be examined before choosing a specific one.

3. According to Fox et al. (2015), SDS-PAGE is not a very precise method for protein quantification because the molecular weight of $\alpha_{s}$-casein and $\beta$ - 
casein are quite similar to each other and SDS-PAGE separates different kinds of proteins based on their molecular weight. Use of High Performance Liquid Chromatography (HPLC) is suggested if conditions are allowed.

4. Previous research indicated that a combination of calcium chelators is able to result in various changes in the physicochemical properties (Kaliappan et al., 2011). Examining the influence of a combination of calcium chelating salts on the foaming properties of reconstituted SMP or micellar casein can be an interesting topic.

5. The appearance of whey protein may influence the foaming properties of the reconstituted samples. As is proved by Kamath et al. (2011), whey proteins may enhance the stability of milk foams. Micellar caseins are suggested to be used to study in future studies. 


\section{REFERENCES}

Augustin, M.A., and P.T. Clarke. 2008. Skim milk powders with enhanced foaming and steam-frothing properties. Dairy Science and Technology Dairy Sci. Technol. 88:149-161. doi:10.1051/dst:2007012.

Barbano, D., and M. Dellavalle. 1987. Rapid Method for Determination of Milk Casein Content by Infrared Analysis. J ournal of Dairy Science. 70:15241528.

Berlin, E., B. Anderson, and M. Pallansch. 1969. Effect of Temperature on Water Vapor Sorption by Dries Milk Powders. J ournal of Dairy Science. 53:146-149. doi:10.3168/jds.s0022-0302(70)86171-9.

Biancuzzo, R.M., A. Young, D. Bibuld, M.H. Cai, M.R. Winter, E.K. Klein, A. Ameri, R. Reitz, W. Salameh, T.C. Chen, and M.F. Holick. 2010. Fortification of orange juice with vitamin D2 or vitamin D3 is as effective as an oral supplement in maintaining vitamin D status in adults. American J ournal of Clinical Nutrition. 91:1621-1626. doi:10.3945/ajcn.2009.27972.

Cayen, M., and B. Baker. 1963. Foodstuff Flavors, Some Factors Affecting the Flavor of Sodium Caseinate. J . Agric. Food Chem. J ournal of Agricultural and Food Chemistry. 11:12-14. doi:10.1021/jf60125a003.

Creamer, L., H. Zoerb, N. Olson, and T. Richardson. 1982. Surface Hydrophobicity of as1 -I, as1 -Casein A and B and Its Implications in Cheese 
Structure. J ournal of Dairy Science. 65:902-906. doi:10.3168/jds.s00220302(82)82289-3.

Damodaran, S., and A. Paraf. 1997. Food proteins and their applications. Marcel Dekker, New York.

Dickinson, E. 1999. Caseins in emulsions: interfacial properties and interactions. International Dairy J ournal. 9:305-312.

Dziuba, J., A. Babuchowski, M. Smoczynski, and Z. Smietana. 1999. Fractal analysis of caseinate structure. International Dairy J ournal. 9:287-292. doi:10.1016/s0958-6946(99)00076-x.

Fox, P.F. 1989. Developments in dairy chemistry. Elsevier Applied Science, London.

Fox, P.F., P.L.H. McSweeney, J.A. O'Mahony, and T. Uniacke-Lowe. 2015. Dairy Chemistry and Biochemistry. Springer International Publishing, Cham.

Fox, P.F., and P.L.H. McSweeney. 2003. Advanced dairy chemistry. Kluwer Academic/Plenum, New York.

Fox, P.F., T. Unibacke-Lowe, P.L.H. Mcsweeney, and J.A. O'mahony. 2015. Dairy Chemistry and Biochemistry. Springer International Publishing, New York, pp. 1657 
Hanrahan, F., A. Tamsma, K. Fox, and M. Pallansch. 1962. Production and Properties of Spray-Dried Whole Milk Foam. J ournal of Dairy Science. 45:27-31. doi:10.3168/jds.s0022-0302(62)89321-7.

Haug, A., A.T. Høstmark, and O.M. Harstad. 2007. Bovine milk in human nutrition - a review. Lipids Health Dis Lipids in Health and Disease. 6:25.

Horne, D.S. 2006. Casein micelle structure: Models and muddles. Current Opinion in Colloid \& Interface Science. 11:148-153. doi:10.1016/j.cocis.2005.11.004.

Huppertz, T. 2010. Foaming properties of milk: A review of the influence of composition and processing. International J ournal of Dairy Technology. 63:477-488. doi:10.1111/j.1471-0307.2010.00629.x.

Kort, E. 2012. Influence of calcium chelators on concentrated micellar casein solutions: from micellar structure to viscosity and heat stability.

Kaliappan, S., and J. Lucey. 2011. Influence of mixtures of calciumchelating salts on the physicochemical properties of casein micelles. Journal of Dairy Science. 94:4255-4263. doi:10.3168/jds.2010-3343.

Kamath S., Deeth H. 2005. Effect of added oil on the foaming properties of skim milk. Milchwissenscaft. 66(4)354-357 
Kamath, S., T. Huppertz, A.V. Houlihan, and H.C. Deeth. 2008. The influence of temperature on the foaming of milk. International Dairy J ournal. 18:994-1002. doi:10.1016/j.idairyj.2008.05.001.

Kamath, S., R. Webb, and H. Deeth. 2011. The composition of interfacial material from skim milk foams. J ournal of Dairy Science. 94:2707-2718. doi:10.3168/jds.2010-3839.

Lin, S.H.C., S.L. Leong, R.K. Dewan, V.A. Bloomfield, and C.V. Morr. 1972. Effect of calcium ion on the structure of native bovine casein micelles. Biochemistry. 11:1818-1821.

Maldonado-Valderrama, J., A. Martín-Rodriguez, M.J. Gálvez-Ruiz, R. Miller, D. Langevin, and M.A. Cabrerizo-Vílchez. 2008. Foams and emulsions of $\beta$-casein examined by interfacial rheology. Colloids and Surfaces $A$ :

Physicochemical and Engineering Aspects. 323:116-122.

doi:10.1016/j.colsurfa.2007.11.003.

Marinova, K.G., E.S. Basheva, B. Nenova, M. Temelska, A.Y. Mirarefi, B. Campbell, and I.B. Ivanov. 2009. Physico-chemical factors controlling the foamability and foam stability of milk proteins: Sodium caseinate and whey protein concentrates. Food Hydrocolloids. 23:1864-1876.

doi:10.1016/j.foodhyd.2009.03.003. 
Mizuno, R., and J.A. Lucey. 2005. Effects of emulsifying salts on the turbidity and calcium-phosphate-protein interactions in casein micelles. J. Dairy Sci. 88:3070-8. doi:10.3168/jds.S0022-0302(05)72988-X.

Mohanty, B., D. Mulvihill, and P. Fox. 1988. Emulsifying and foaming properties of acidic caseins and sodium caseinate. Food Chemistry. 28:17-30. doi:10.1016/0308-8146(88)90003-9.

Murray, B.S. 2007. Stabilization of bubbles and foams. Current O pinion in Colloid \& Interface Science. 12:232-241. doi:10.1016/j.cocis.2007.07.009.

Murray, B.S., and R. Ettelaie. 2004. Foam stability: proteins and nanoparticles. Current O pinion in Colloid \& Interface Science. 9:314-320. doi:10.1016/j.cocis.2004.09.004.

O' Donnell, S., A. Cranney, T. Horsley, H.A. Weiler, S.A. Atkinson, D.A. Hanley, D.S. Ooi, L. Ward, N. Barrowman, M. Fang, M. Sampson, A. Tsertsvadze, and F. Yazdi. 2008. Efficacy of food fortification on serum 25hydroxyvitamin D concentrations: systematic review. American Journal of Clinical Nutrition. 88:1528-1534. doi:10.3945/ajen.2008.26415.

Oetjen, K., C. Bilke-Krause, M. Madani, and T. Willers. 2014. Temperature effect on foamability, foam stability, and foam structure of milk. Colloids and Surfaces A: P hysicochemical and Engineering Aspects. 460:280285. doi:10.1016/j.colsurfa.2014.01.086. 
Phadungath, C. 2005. Casein micelle structure: a concise review. J. Sci. Technol. 27:201-212.

Phelan, M., A. Aherne, R.J. Fitzgerald, and N.M. O'brien. 2009. Caseinderived bioactive peptides: Biological effects, industrial uses, safety aspects and regulatory status. International Dairy J ournal. 19:643-654. doi:10.1016/j.idairyj.2009.06.001.

Phillips, L.G., Z. Haque, and J.E. Kinsella. 1987. A Method for the Measurement of Foam Formation and Stability. J ournal of Food Science J Food Science. 52:1074-1077. doi:10.1111/j.1365-2621.1987.tb14279.x.

Pilhofer, G.M., H.-C. Lee, M.J. Mccarthy, P.S. Tong, and J.B. German. 1994. Functionality of Milk Fat In Foam Formation and Stability. J ournal of Dairy Science. 77:55-63.

Roginski, H., J.W. Fuquay, and P.F. Fox. 2003. Encyclopedia of dairy science. Academic Press, London.

Rouimi, S., C. Schorsch, C. Valentini, and S. Vaslin. 2005. Foam stability and interfacial properties of milk protein?surfactant systems. Food Hydrocolloids. 19:467-478. doi:10.1016/j.foodhyd.2004.10.032.

Sanchez, C., and J. Patino. 2005. Interfacial, foaming and emulsifying characteristics of sodium caseinate as influenced by protein concentration in solution. Food Hydrocolloids. 19:407-416. doi:10.1016/j.foodhyd.2004.10.007. 
Sceni, P., and J. Wagner. 2007. Study on Sodium Caseinate Foam Stability by Multiple Light Scattering. Food Science and Technology International. 13:461-468.

Sharma, A., A.H. Jana, and R.S. Chavan. 2012. Functionality of Milk Powders and Milk-Based Powders for End Use Applications-A Review. Comprehensive Reviews in Food Science and Food Safety. 11:518-528.

Sutermeister, E. 1939. Casein and its industrial applications. Reinhold Pub. Corp., New York.

Swaisgood, H.E. 1993. Review and Update of Casein Chemistry. Journal of Dairy Science. 76:3054-3061. doi:10.3168/jds.s0022-0302(93)77645-6.

USDA. 2015. National Nutritient Database for Standard Reference Release 28. Accessed May 4, 2016. https://ndb.nal.usda.gov/ndb/foods/search

Walsh, D.J., K. Russell, and R.J. Fitzgerald. 2008. Stabilisation of sodium caseinate hydrolysate foams. Food Research International. 41:43-52. doi:10.1016/j.foodres.2007.09.003.

Walstra, P. 1990. On the Stability of Casein Micelles. J ournal of Dairy Science. 73:1965-1979.

Walstra, P., J.T.M. Wouters, and T.J. Geurts. 2006. Dairy science and technology. CRC/Taylor \& Francis, Boca Raton. 
Wilde, P.T., and Clark, D.C. 1996. 5. Foam formation and stability. In Hall, G.M. ed. Methods of testing protein functionality. Blackie Academic \& Professional, London.

Zhang, Z., and H. Goff. 2004. Protein distribution at air interfaces in dairy foams and ice cream as affected by casein dissociation and emulsifiers. International Dairy J ournal. 14:647-657. doi:10.1016/j.idairyj.2003.12.007.

Zhao, Z., and M. Corredig. 2016. Short communication: Serum composition of milk subjected to re-equilibration by dialysis at different temperatures, after pH adjustments. Journal of Dairy Science. 99:2588-2593. doi:10.3168/jds.2015-9917. 


\section{APPENDICES}

1. Statistical Analysis of Foamability among all Treatments.

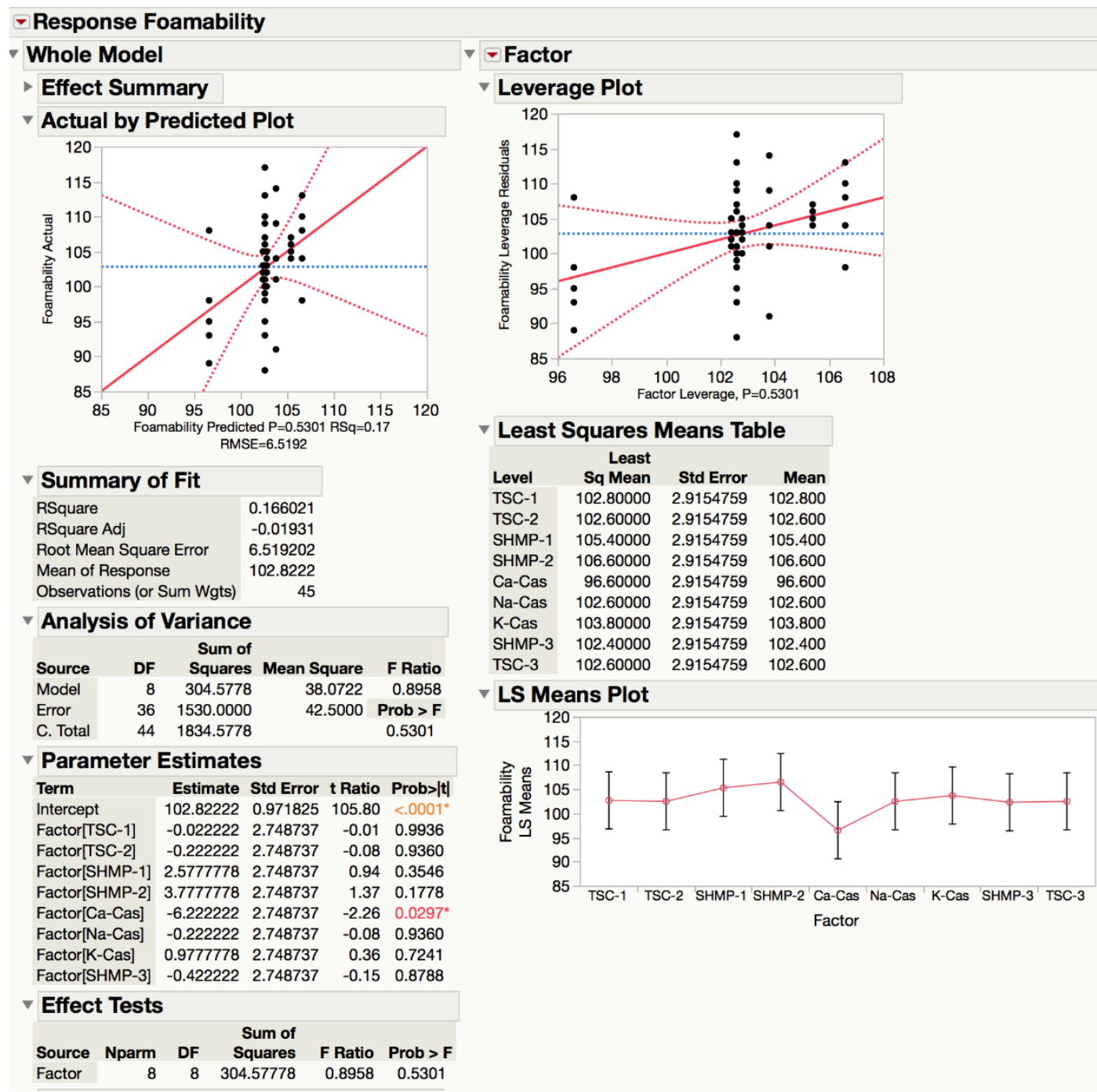




\section{Statistical Analysis of Foamability among Chelated Reconstituted SMP.}

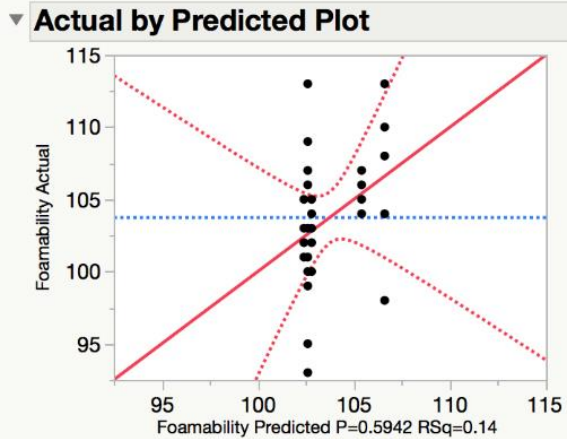
RMSE $=4.6494$

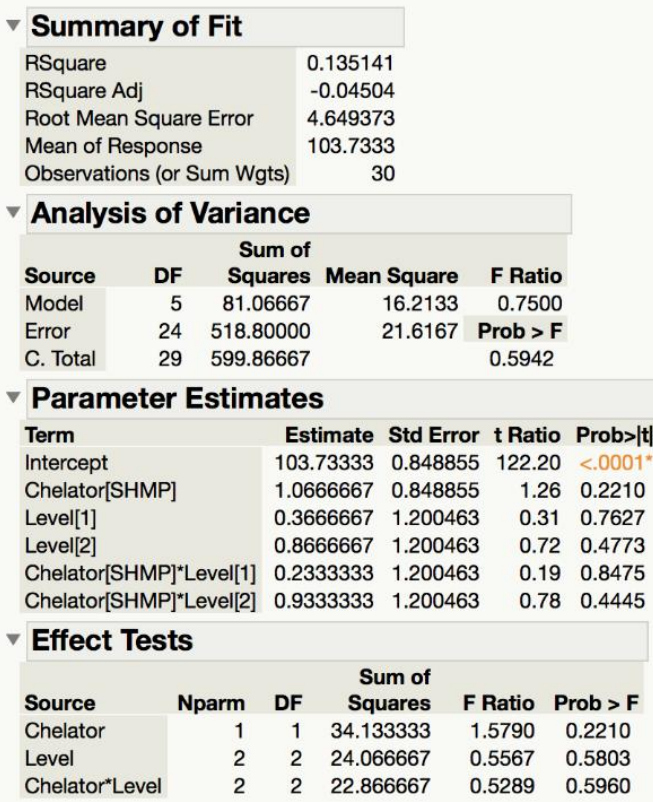

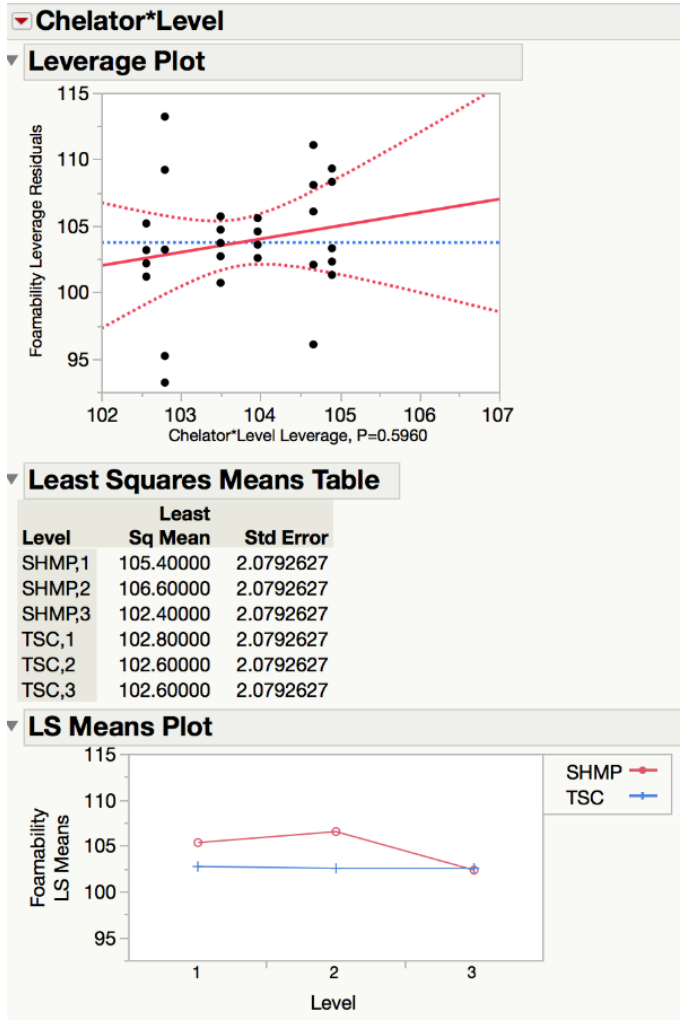




\section{Statistical Analysis of Foam Stability among all Treatments.}
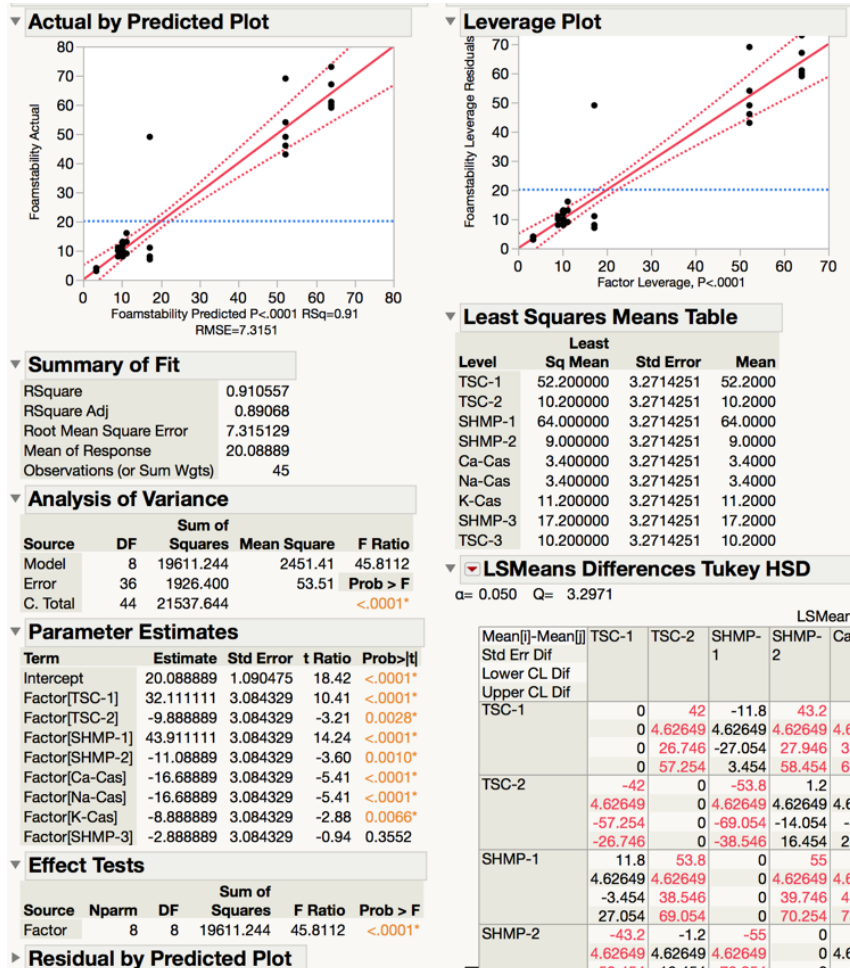

$a=0.050 \quad Q=3.2971$
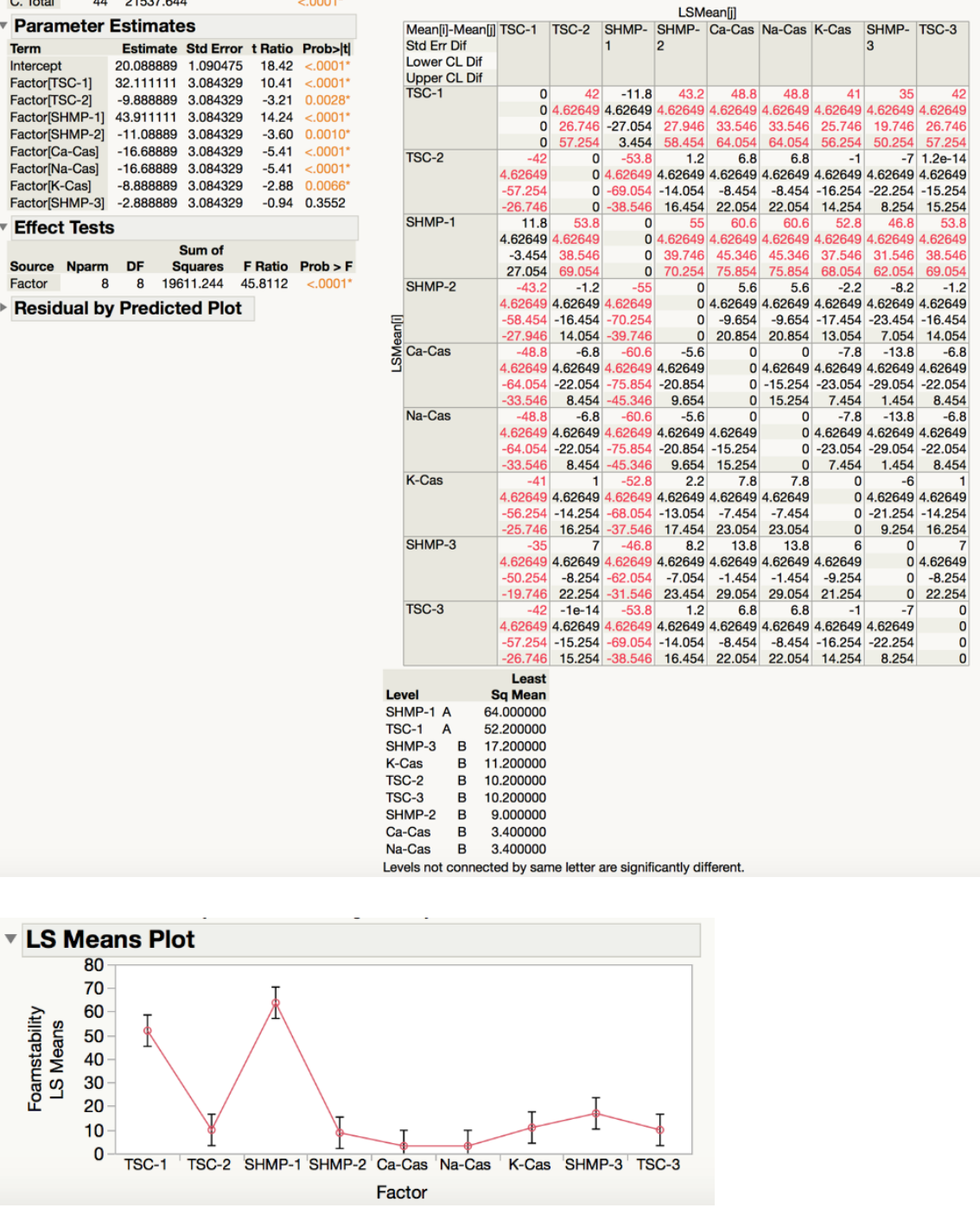


\section{Statistical Analysis of Foam Stability among Chelated Reconstituted SMP.}

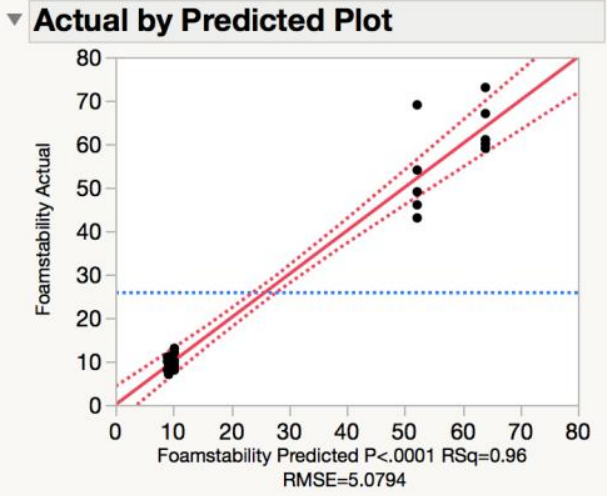

- Summary of Fit

RSquare

RSquare Adj

Root Mean Square Error

Mean of Response

Observations (or Sum Wgts)

- Analysis of Variance

$\begin{array}{lrrrr}\text { Source } & \text { DF } & \begin{array}{r}\text { Sum of } \\ \text { Squares }\end{array} & \text { Mean Square } & \text { F Ratio } \\ \text { Model } & 5 & 16003.600 & 3200.72 & 124.0589 \\ \text { Error } & 24 & 619.200 & 25.80 & \text { Prob }>\text { F } \\ \text { C. Total } & 29 & 16622.800 & & <.0001^{*}\end{array}$

\section{จ Parameter Estimates}

Term

Intercept

Chelator[SHMP]

Level[1]

Level[2]

Chelator[SHMP]*Level[1]

Chelator[SHMP]*Level[2]

\section{$\checkmark$ Effect Tests}

$\begin{array}{lrrrrr}\text { Source } & \text { Nparm } & \text { DF } & \begin{array}{r}\text { Sum of } \\ \text { Squares }\end{array} & \text { F Ratio } & \text { Prob > F } \\ \text { Chelator } & 1 & 1 & 76.800 & 2.9767 & 0.0973 \\ \text { Level } & 2 & 2 & 15649.400 & 303.2829 & <.0001^{*} \\ \text { Chelator*Level } & 2 & 2 & 277.400 & 5.3760 & 0.0118^{*}\end{array}$
$\begin{array}{llrr}1.6 & 0.927362 & 1.73 & 0.0973\end{array}$

$32.3 \quad 1.311488 \quad 24.63<.0001$ $\begin{array}{lllll}-16.2 & 1.311488 & -12.35<.0001\end{array}$ $\begin{array}{llll}4.3 & 1.311488 & 3.28 & 0.0032\end{array}$ $\begin{array}{llll}-2.2 & 1.311488 & -1.68 & 0.1064\end{array}$

\subsection{5}

0.95499

5.07937

25.8

30

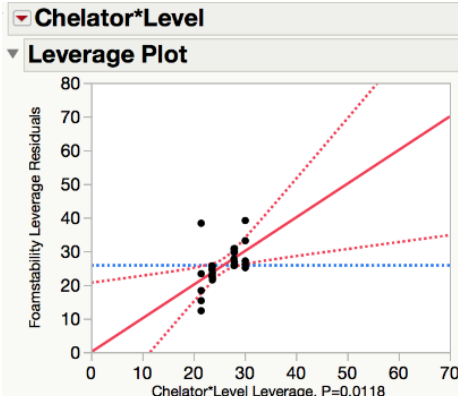

- Least Squares Means Table

$\checkmark$ Least Squares Means Tab
Least

$\begin{array}{lrr}\text { Level Sq Mean } & \text { Std Error } \\ \text { SHMP1 } & 64.000000 & 2.2715633\end{array}$

\begin{tabular}{lrr} 
SHMP, 1 & 64.000000 & 2.2715633 \\
\hline
\end{tabular}

SHMP,2 $9.000000 \quad 2.2715633$

SHMP, $3 \quad 9.200000 \quad 2.2715633$

$\begin{array}{lll}\text { TSC, } 2 & 10.200000 & 2.2715633\end{array}$

$\begin{array}{lll}\text { TSC,3 } & 10.200000 & 2.2715633\end{array}$

v LS Means Plot

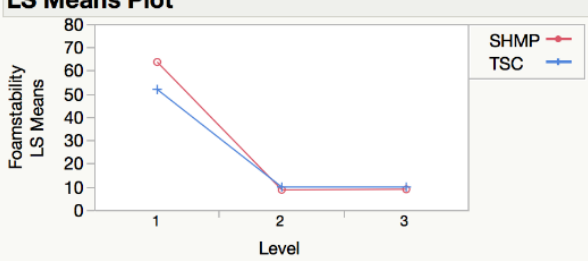

- LSMeans Differences Tukey HSD

$\mathrm{a}=0.050 \quad \mathrm{Q}=3.09193$

LSMean[i]

\begin{tabular}{ll|l|l} 
Mean[i]-Mean[i] SHMP,1 SHMP,2 SHMP,3 TSC,1 & TSC,2 & TSC,3
\end{tabular} Std Err Dif

Lower CL Dif

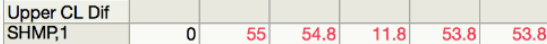

\begin{tabular}{|l|l|l|l|l|l|l|}
\hline SHMP, & 0 & 55 & 54.8 & 11.8 & 53.8 & 53. \\
\hline
\end{tabular} $045.067244 .86721 .86724 \quad 43.867243 .8672$ \begin{tabular}{ll|l|l|l|l|l|l|l}
0 & 64.9328 & 64.7328 & 21.7328 & 63.7328 & 63.732
\end{tabular}

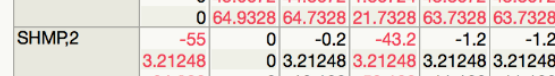

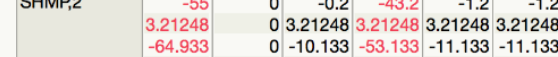
\begin{tabular}{l|l|l|l|l|l|l|l|}
-45.067 & 09.73276 & -33.2678 .732768 .73276 \\
\hline
\end{tabular}

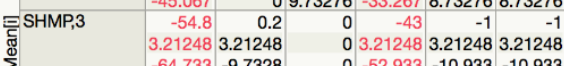

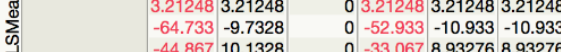

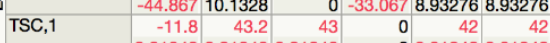

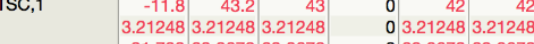
$\begin{array}{llll}-21.733 & 33.267233 .0672 & 0 & 32.067232 .0672\end{array}$

\begin{tabular}{|r|r|r|r|r|r|r|r|} 
& -1.8672 & 53.1328 & 52.9328 & 0 & 51.9328 & 51.9328 \\
\hline TSC,2 & -53.8 & $\mathbf{1 . 2}$ & $\mathbf{1}$ & -42 & 0 & 0
\end{tabular}

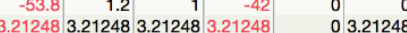

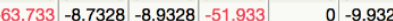

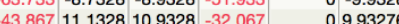
$\begin{array}{llll}25.8 & 0.927362 & 27.82<.0001\end{array}$

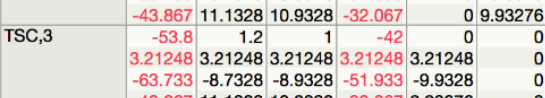

$-6.733-8.7328-8.9328$
$-51.933-9.9328$

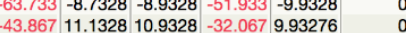

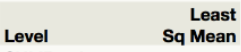

Level Mean
SHMP,1 A

\begin{tabular}{ll} 
TSC 1 B & 64.000000 \\
\hline
\end{tabular}

$\begin{array}{lll}\text { TSC,1 } & \text { B } & 52.200000 \\ \text { TSC,2 } & \text { C } & 10.200000\end{array}$

TSC,3 C 10.200000

SHMP,3 C 9.200000

SHMP,2 C 9.000000

Levels not connected by same letter are significantly different. 


\section{Statistical Analysis of Preferential Locations of $\alpha_{s}$-casein.}

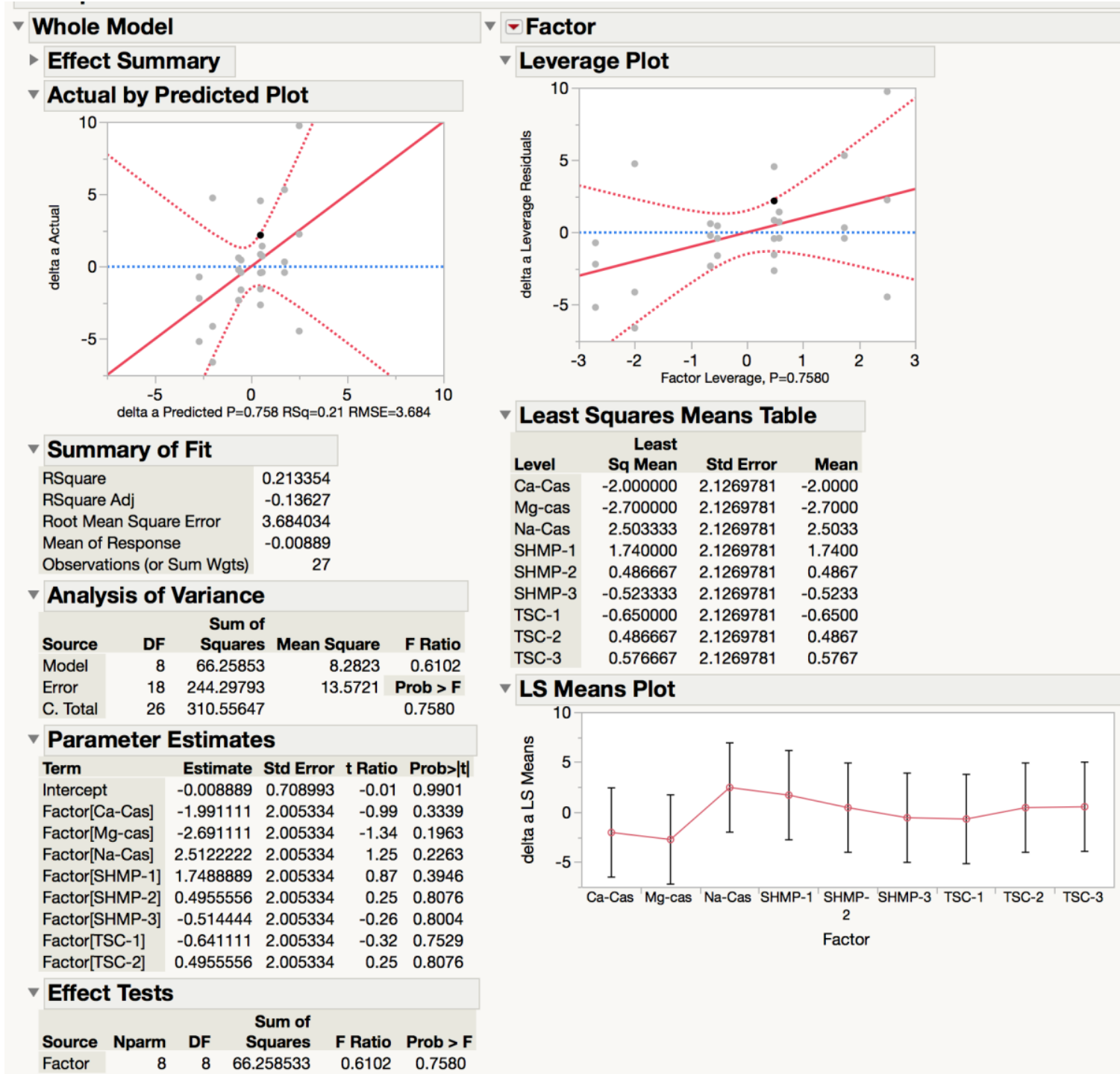




\section{Statistical Analysis of Preferential Locations of $\beta$-casein.}

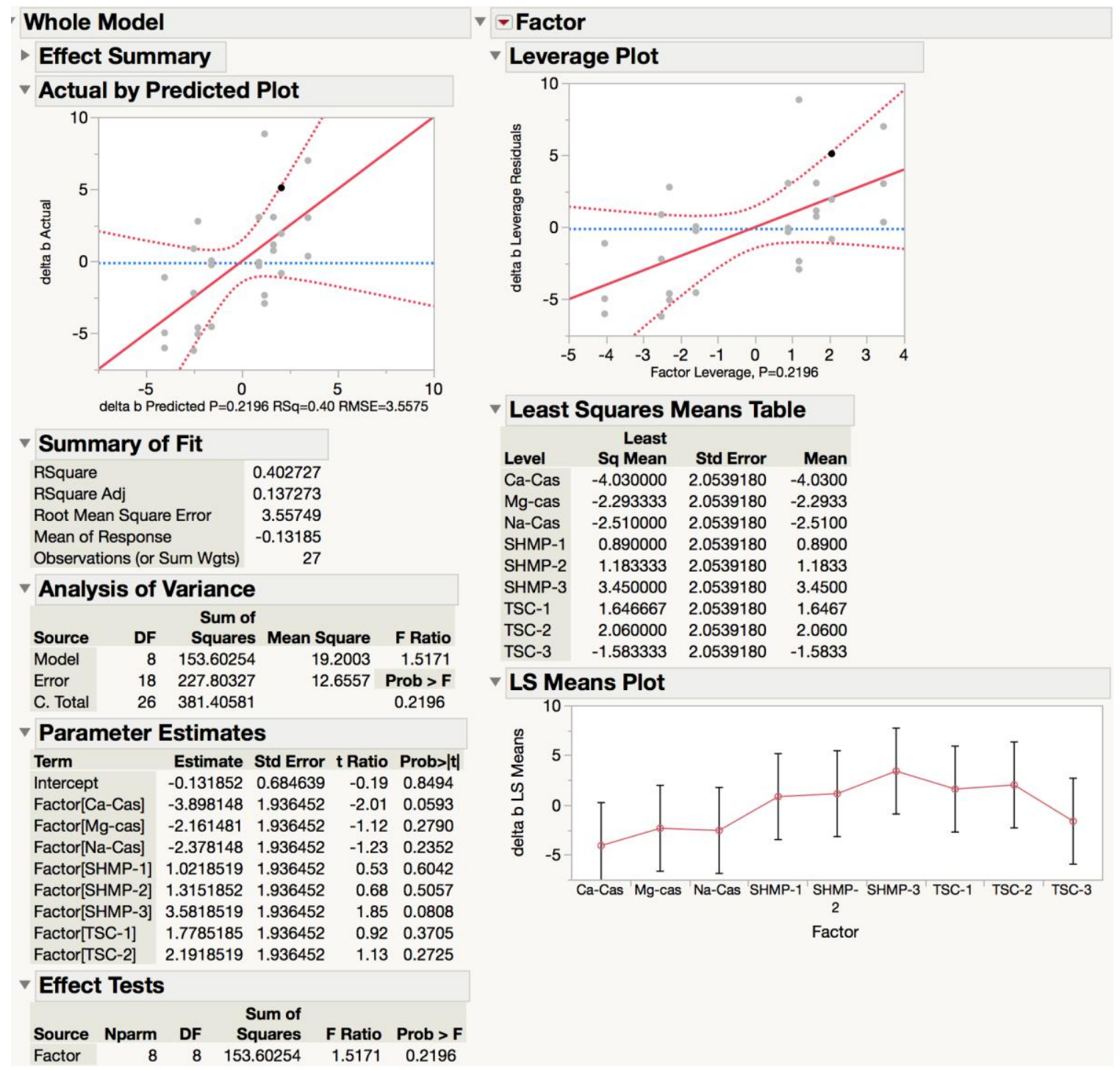




\section{Statistical Analysis of Preferential Locations of $\kappa$-casein.}

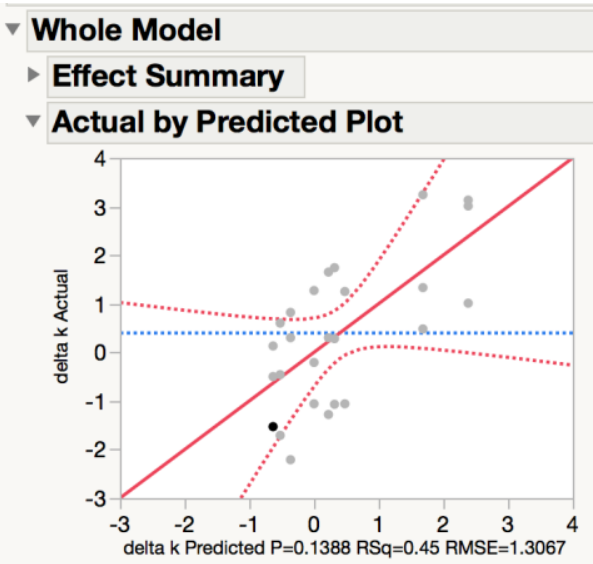

\begin{tabular}{lr}
\hline Summary of Fit & \\
\hline RSquare & 0.447183 \\
RSquare Adj & 0.201486 \\
Root Mean Square Error & 1.306721 \\
Mean of Response & 0.395926 \\
\hline Observations (or Sum Wgts) & 27 \\
\hline
\end{tabular}

$\checkmark$ Analysis of Variance

Source DF Squares Mean Square F Ratio $\begin{array}{lrrrr}\text { Model } & 8 & 24.862319 & 3.10779 & 1.8201\end{array}$

$\begin{array}{llllll}\text { Error } & 18 & 30.735333 & 1.70752 \text { Prob }>\text { F }\end{array}$

$\begin{array}{llll}\text { C. Total } & 26 & 55.597652 & 0.1388\end{array}$

\section{$\checkmark$ Parameter Estimates}

Term Estimate Std Error t Ratio Prob $>|\mathrm{t}|$ $\begin{array}{lllll}\text { Intercept } & 0.3959259 & 0.251478 & 1.57 & 0.1328\end{array}$ Factor[Ca-Cas] $\quad-0.079259 \quad 0.711289 \quad-0.11 \quad 0.9125$ $\begin{array}{llllll}\text { Factor[Mg-cas] } & 1.9874074 & 0.711289 & 2.79 & 0.0120\end{array}$ Factor[Na-Cas] $\quad-0.172593 \quad 0.711289 \quad-0.24 \quad 0.8110$ Factor[SHMP-1] $\quad-0.919259 \quad 0.711289 \quad-1.29 \quad 0.2126$ $\begin{array}{lllll}\text { Factor[SHMP-2] } & -0.395926 & 0.711289 & -0.56 & 0.5846\end{array}$ Factor[SHMP-3] $1.2874074 \quad 0.711289 \quad 1.81 \quad 0.0870$ $\begin{array}{llllll}\text { Factor[TSC-1] } & 0.0807407 & 0.711289 & 0.11 & 0.9109\end{array}$ $\begin{array}{lllll}\text { Factor[TSC-2] } & -1.029259 & 0.711289 & -1.45 & 0.1651\end{array}$

\section{$\checkmark$ Effect Tests}

\begin{tabular}{|c|c|c|c|c|c|}
\hline & Nparm & DF & $\begin{array}{l}\text { Sum of } \\
\text { Squares }\end{array}$ & F Ratio & Prob $>F$ \\
\hline Factc & 8 & 8 & 24.862319 & 1.8201 & 0.1388 \\
\hline
\end{tabular}

\section{$\checkmark$ Factor \\ $\checkmark$ Leverage Plot}

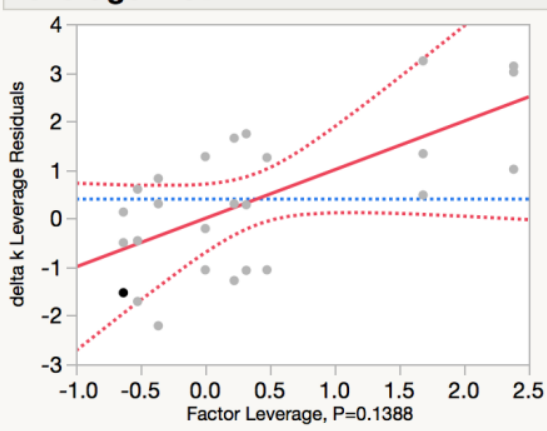

Least Squares Means Table

\begin{tabular}{lrrrr}
\hline Level & $\begin{array}{r}\text { Least } \\
\text { Sq Mean }\end{array}$ & $\begin{array}{r}\text { Std Error } \\
\text { Mean }\end{array}$ \\
Ca-Cas & 0.316667 & 0.75443544 & 0.3167 \\
Mg-cas & 2.383333 & 0.75443544 & 2.3833 \\
Na-Cas & 0.223333 & 0.75443544 & 0.2233 \\
SHMP-1 & -0.523333 & 0.75443544 & -0.5233 \\
SHMP-2 & $5.5511 \mathrm{e}-17$ & 0.75443544 & $2.22 \mathrm{e}-16$ \\
SHMP-3 & 1.683333 & 0.75443544 & 1.6833 \\
TSC-1 & 0.476667 & 0.75443544 & 0.4767 \\
TSC-2 & -0.633333 & 0.75443544 & -0.6333 \\
\hline TSC-3 & -0.363333 & 0.75443544 & -0.3633
\end{tabular}

$\checkmark$ LS Means Plot

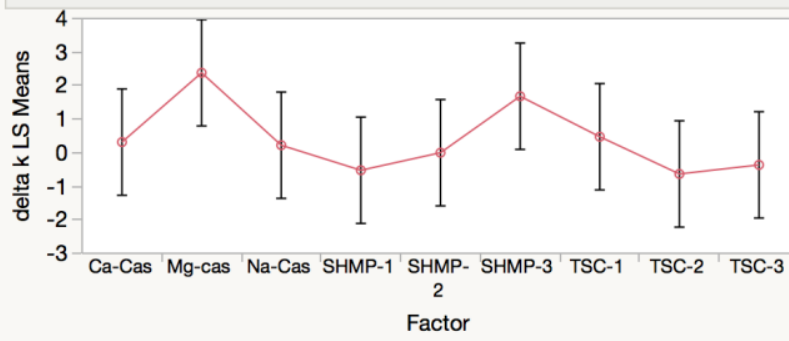


8. Foamability $(\mathrm{mL})$ and Half-life $(\mathrm{min})$ of Non-treated SMP and Micellar Casein Solutions.

\begin{tabular}{|l|l|c|c|}
\hline & \multicolumn{1}{|c|}{ Treatment } & Foamability $(\mathrm{mL})$ & Half-life (min) \\
\hline 1. & SMP & 99 & 27 \\
\hline 2. & Micellar Casein & 98 & 0 \\
\hline 3. & SMP & 99 & 33 \\
\hline 4. & Micellar Casein & 88 & 0 \\
\hline 5. & SMP & 110 & 32 \\
\hline 6. & Micellar Casein & 89 & 0 \\
\hline 7. & Micellar Casein & 95 & 0 \\
\hline 8. & Micellar Casein & 94 & 0 \\
\hline 9. & SMP & 104 & 36 \\
\hline 10. & SMP & 100 & 32 \\
\hline 11. & SMP & 104 & 29 \\
\hline 12. & Micellar Casein & 100 & 0 \\
\hline
\end{tabular}


9. Statistical Analysis on the Foamability between the Non-treated SMP and Micellar Casein Solutions.

\section{2-Sample t: Foamability $(\mathrm{mL})$ by Treatments}

\section{Method}

$\mu_{1}$ : mean of Foamability $(\mathrm{mL})$ when Treatments $=$ Micellar Casein

$\mu_{2}$ : mean of Foamability $(\mathrm{mL})$ when Treatments = SMP

Difference: $\mu_{1}-\mu_{2}$

Equal variances are not assumed for this analysis.

Descriptive Statistics: Foamability $(\mathrm{mL})$

\begin{tabular}{lrrrr}
\multicolumn{1}{c}{ Treatments } & N & \multicolumn{1}{c}{ Mean } & StDev & SE Mean \\
\hline Micellar Casein & 6 & 94.000 & 4.775 & 1.949 \\
SMP & 6 & 102.667 & 4.274 & 1.745
\end{tabular}

Estimation for Difference

\begin{tabular}{rc} 
Difference & $95 \% \mathrm{Cl}$ for Difference \\
\hline-8.667 & $(-14.585,-2.748)$
\end{tabular}

\section{Test}

$$
\text { Null hypothesis } \quad \mathrm{H}_{0}: \mu_{1}-\mu_{2}=0
$$

Alternative hypothesis $\mathrm{H}_{1}: \mu_{1}-\mu_{2} \neq 0$

\begin{tabular}{rrr} 
T-Value & DF & P-Value \\
\hline-3.31 & 9 & 0.0090
\end{tabular}


10. Statistical Analysis on the Foam Stability between the Non-treated SMP and Micellar Casein Solutions.

\section{One-Way ANOVA: Half-life (min) versus Treatments}

\section{Method}

Null hypothesis All means are equal

Alternative hypothesis At least one mean is different

Significance level $\quad a=0.05$

Equal variances were assumed for the analysis.

Factor Information

\begin{tabular}{crc} 
Factor & Levels & Values \\
\hline Treatments & 2 & Micellar Casein, SMP
\end{tabular}

Analysis of Variance

\begin{tabular}{lrrrrr}
\multicolumn{1}{c}{ Source } & DF & Adj SS & Adj MS & F-Value & P-Value \\
\hline Treatments & 1 & 2976.75 & 2976.75 & 601.36 & $<0.0001$ \\
Error & 10 & 49.50 & 4.95 & & \\
Total & 11 & 3026.25 & & &
\end{tabular}

Model Summary

\begin{tabular}{ccrr} 
S & R-sq & R-sq(adj) & R-sq(pred) \\
\hline 2.22485955 & $98.36 \%$ & $98.20 \%$ & $97.64 \%$
\end{tabular}

Means

\begin{tabular}{lrrrr}
\multicolumn{1}{c}{ Treatments } & N & Mean & StDev & \multicolumn{1}{c}{$95 \% \mathrm{Cl}$} \\
\hline Micellar Casein & 6 & 0 & 0 & $(-2.02380762,2.02380762)$ \\
SMP & 6 & 31.500 & 3.146 & $(29.476,33.524)$ \\
Pooled StDev $=2.22485955$ & &
\end{tabular}

